\title{
The Diels-Alder Reaction in Steroid Synthesis
}

\author{
Emily G. Mackay \\ Michael S. Sherburn*
}

Research School of Chemistry, Building 137, Sullivans Creek Road, Australian National University, Canberra, ACT 0200, Australia

michael.sherburn@anu.edu.au

Dedicated to Professor Lew Mander on the occasion of his $75^{\text {th }}$ birthday

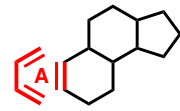<smiles>C1=CCCC2C(CCC1)CCC1CCCC12</smiles><smiles>C=CC1CCCCC1CCC1CCCC1=C</smiles><smiles>C=CCCCC1=CCCC2CCCCC12</smiles><smiles>C1=CC=CC=1</smiles><smiles>C=C/C=C\CC1C(/C=C\C)CCC2CCCC21</smiles><smiles>C=C1CCCCC1CCCC1CCCC1</smiles><smiles>C=C[C@H]1CCCCC1=C1CCCC1CC</smiles>

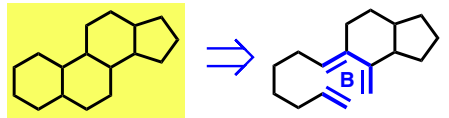<smiles>C/C=C1/CCCC2CCCC12</smiles><smiles>C=CC1CCCC1CCCCC</smiles><smiles>C1=CC(/C=C/CC2CCCCC2)CCCC1</smiles><smiles>C=CC1CCCCC1C#CC1CCCC1</smiles><smiles>C1=CC2CCCCC2CCC1</smiles>

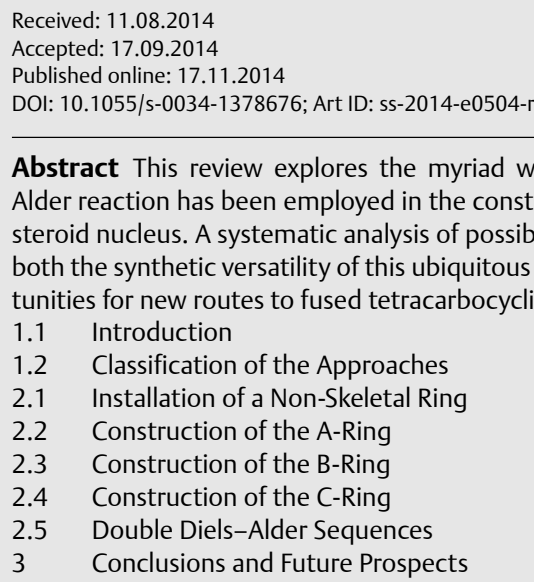

1.1 Introduction

1.2 Classification of the Approaches

2.1 Installation of a Non-Skeletal Ring

2.2 Construction of the A-Ring

2.3 Construction of the B-Ring

2.4 Construction of the C-Ring

2.5 Double Diels-Alder Sequences

3 Conclusions and Future Prospects

Abstract This review explores the myriad ways in which the DielsAlder reaction has been employed in the construction of the tetracyclic steroid nucleus. A systematic analysis of possible approaches highlights both the synthetic versatility of this ubiquitous reaction and also opportunities for new routes to fused tetracarbocyclic steroid frameworks.

Key words steroids, Diels-Alder reaction, total synthesis, cycloadditions, synthetic methodology

\subsection{Introduction}

Their rich and varied roles in the plant, animal and fungal kingdoms make steroids perhaps the most thoroughly investigated natural products. Steroids are classified by the IUPAC as 'compounds possessing the skeleton of cyclopenta[ $\alpha]$ phenanthrene or a skeleton derived therefrom. ${ }^{1}$ The steroid family of structures is, therefore, both complex and diverse (Figure 1 ).

Since the discovery and first characterization of steroids in the 1920s and 1930s, ${ }^{2}$ chemists have been immersed in the challenge of their synthesis. With their tetracyclic core containing up to four six-membered rings, steroids are ideal targets for the use of the Diels-Alder (DA) reaction. ${ }^{3}$

There are 18 possible ways in which a single DA reaction can be used to generate the six-membered rings of the archetypal 6,6,6,5 steroid ring system, 14 of which have been

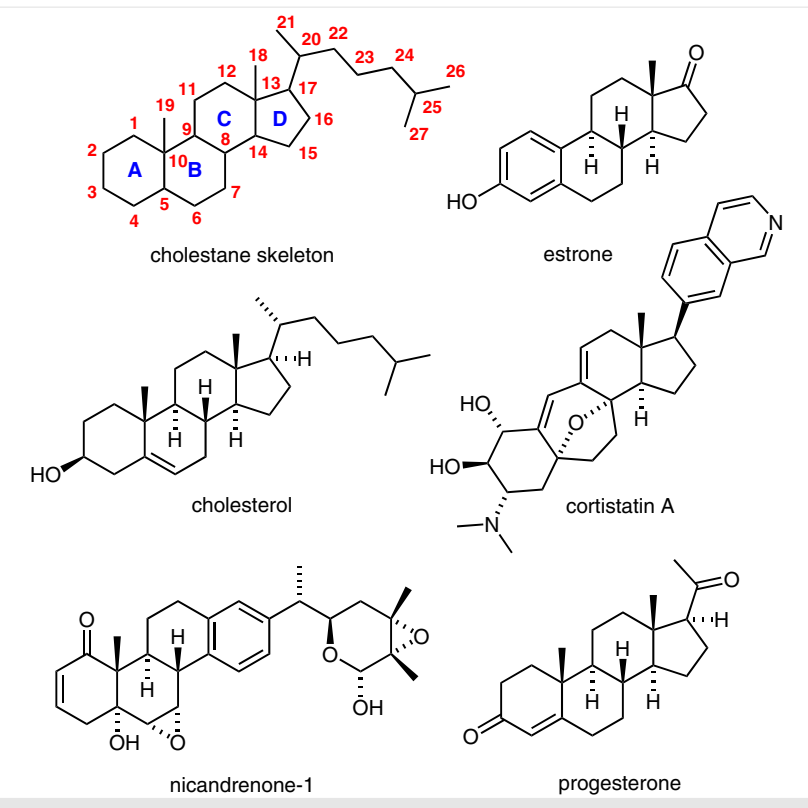

Figure 1 Selected steroid natural products

reported. This number expands when the more exotic steroid skeletons, such as the 6,6,6,6 (cf. nicandrenone-1, Figure 1 ) or 6,7,6,5 systems (cf. cortistatin A, Figure 1) are included.

The utility of the DA reaction in the construction of the steroid skeleton dates back to 1937.4 In the first report, by Cohen and Warren, the C-ring was formed by way of a DA reaction between 1-vinylnaphthalene (1) and maleic anhydride (2), and an acid-catalyzed alkene isomerization to give naphthalene $\mathbf{3}$ (Scheme 1). On exposure to sodium hydroxide and dimethyl sulfate, the anhydride was converted into diester $\mathbf{4}$, which in turn underwent a regioselective intermolecular Claisen condensation with ethyl acetate to 
give keto diester 5. Dieckmann condensation and hydrolysis gave diketo acid $\mathbf{6}$, which underwent decarboxylation in situ to give the tetracarbocyclic product 7.<smiles>C=Cc1cccc2ccccc12</smiles>

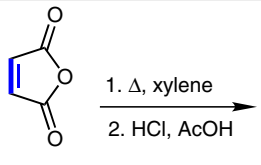

2<smiles>CCOC(=O)CC(=O)C1CCc2c(ccc3ccccc23)C1C(=O)OCC</smiles>

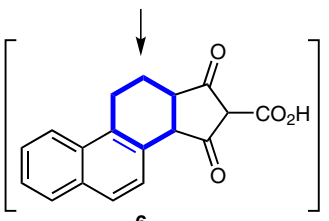<smiles>O=C1OC(=O)C2c3ccc4ccccc4c3CCC12</smiles>

3

$\mathrm{Me}_{2} \mathrm{SO}_{4}$ aq $\mathrm{NaOH}$<smiles>COC(=O)C1c2ccc3ccccc3c2C[C@@H](O)C1C(=O)OC</smiles>

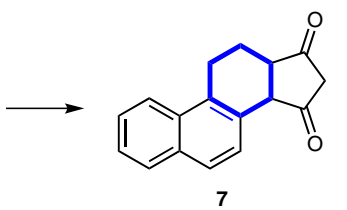

Scheme 1 Cohen and Warren's 1937 synthesis of the steroid skeleton (stereochemistry and yields not reported)

A large number of steroid syntheses featuring the DA reaction have since been reported. This review focuses on publications describing the formation of the tetracyclic steroid ring system, and the myriad roles the DA reaction has played in the realization of this goal. One previous review on this topic covering the literature from 1983-2009 has appeared. ${ }^{5}$

\subsection{Classification of the Approaches}

The use of the DA reaction in the synthesis of the $6,6,6,5$ steroid ring system can be divided into five main categories: the first three are those involving a single DA reaction in the direct formation of the A-ring, the B-ring, or the Cring. Certain intramolecular Diels-Alder (IMDA) reactions lead not only to the direct formation of one steroid ring (specifically, the one formed by union of diene and dienophile) but also to the indirect formation of a second ring (from cyclization of the diene-dienophile tether). For simplicity of presentation, we chose to include such IMDA approaches within the main A-ring, B-ring or C-ring synthesis categories. The remaining two categories comprise (a) syntheses that use more than one DA reaction in the formation of the steroid skeleton, and (b) those in which the DA reaction forms a ring that is not included in the final tetracyclic framework. A somewhat counterintuitive strategy, this last approach has nonetheless been adopted successfully in a variety of contexts. We begin our review with this last class of approaches, before moving on to the A-through C-ringforming examples, concluding with examples of double DA sequences in steroid synthesis.

\subsection{Installation of a Non-Skeletal Ring}

The first example using this approach comes from the great R. B. Woodward, in his 1952 formal synthesis of progesterone, desoxycorticosterone, testosterone, androsterone, cholesterol and cortisone. ${ }^{6}$ A DA reaction between 1,3-butadiene and the more electron-deficient alkene of

\section{Biographical Sketches}

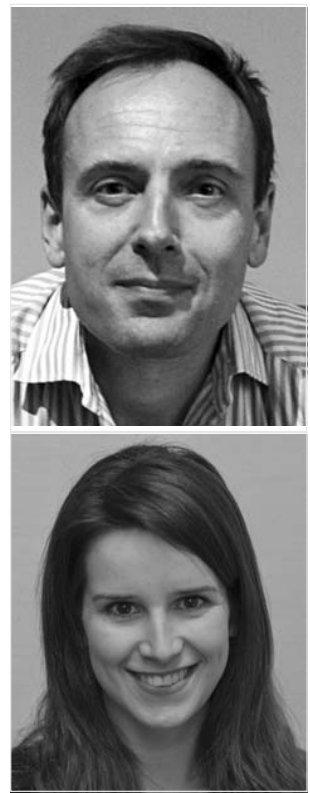

Professor Michael Sherburn studied chemistry at the University of Nottingham, UK, and received his Ph.D. in 1991 with John A. Murphy. He then moved to Australia and worked as a post-doctoral fellow in the Research School of Chemis-

Emily Mackay obtained a Bachelor of Biomedical Science (Honours, $1^{\text {st }}$ class) from Victoria University of Wellington in 2009. She commenced doctoral studies at the try, the Australian National University (ANU) with Lewis $\mathrm{N}$. Mander. He held academic positions at Massey University in New Zealand and the University of Sydney before being appointed at the Research School of Chemistry,
ANU in 2002. His awards include the Le Fèvre Memorial Prize of the Australian Academy of Science (2006) and the A. J. Birch Medal of the RACl (2008).

Australian National University in 2010 , under the supervision of Professor Michael Sherburn, submitting in early 2014. She is currently working as a postdoctoral fellow in the Sherburn research group. Her research interests focus on the application of the Diels-Alder reaction in targetoriented synthesis. 
disubstituted $p$-benzoquinone $\mathbf{8}$ as dienophile gave bicycle 9 (Scheme 2). A further seven reactions were required to generate diketone 10, which underwent an intramolecular aldol condensation to install what would eventually become the steroid B-ring. The product, tricycle 11, was manipulated in a similar manner to annelate the A-ring by way of carboxylic acid $\mathbf{1 2}$ into tetracycle 13. The final phase of the synthesis involved ring contraction of the D-ring of Dhomosteroid 13. Acetal hydrolysis and cleavage of the resulting 1,2-diol to the dialdehyde was brought about by exposure to periodic acid. Intramolecular aldol condensation then gave cyclopentenal 14, an advanced intermediate in the synthesis. Stepwise ring introduction through the combined use of Michael and aldol chemistry (namely, Robinson annelation and variants thereupon) is a feature common to many of the earlier examples in this review, and early steroid syntheses more generally. From a strategic perspective, Woodward's approach is unexpected since it employs a DA reaction to incorporate the carbons of the only carbocycle in the steroid framework that is not six-membered. The cyclohexene ring, formed in the DA reaction $\mathbf{8} \rightarrow \mathbf{9}$, serves as a protected form of the cyclopentane D-ring, which is skillfully revealed late in the synthesis.
The next example of a DA reaction forming a non-skeletal ring is seen in Ireland's 1977 construction of the fusidic acid nucleus. ${ }^{7}$ In this report, a hetero-DA reaction between 1,1-disubstituted dienophile 15 and enone 16 gave dihydropyran 17 in excellent yield (Scheme 3). The enol ether was hydrolyzed then further elaborated into diketone $\mathbf{1 8}$, which underwent an intramolecular aldol condensation to form enone 19. An intramolecular aldol condensation was also employed to form the A-ring of D-homosteroid 21 via ketone 20. This is an intriguing use of the DA reaction, with the overall conversion $\mathbf{1 6} \rightarrow \mathbf{1 8}$ achieving the equivalent of a Michael addition and stereoselective enolate alkylation.

Stork's 1987 approach to adrenosterone is a classic example of the strategic use of the DA reaction in total synthesis (Scheme 4). ${ }^{8}$ The synthesis draws upon methodology originally reported in $1981 .^{9}$ The DA precursor $\mathbf{2 4}$ was prepared from keto acid 22, by treatment with four molar equivalents of isopropenyllithium to give tertiary allylic alcohol 23, which was dehydrated with the Burgess reagent. ${ }^{10}$ The DA reaction ensued upon exposure of $\mathbf{2 4}$ to trifluoroacetic acid in dichloromethane, providing tetracycle $\mathbf{2 5}$ in good yield. The $\pi$-diastereofacial selectivity of this reaction is controlled by the configuration of the stereocenter at C8 in precursor 24, which places the dienophile on the lower face of the diene. Only the desired endo isomer $\mathbf{2 5}$ was re-

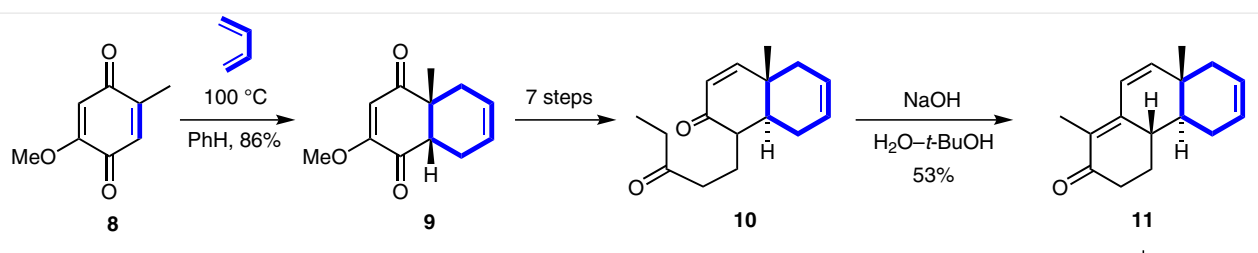

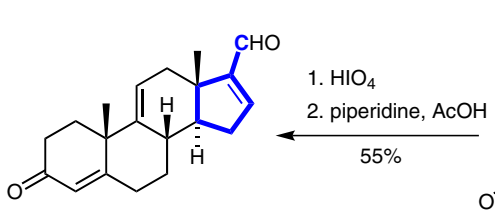

14

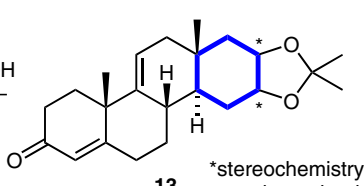

13 not determined

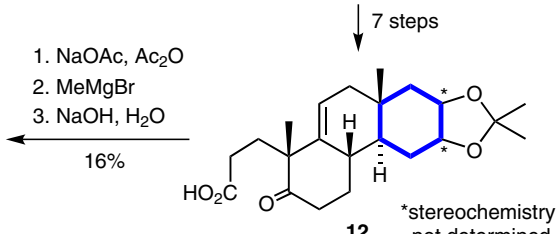

Scheme 2 Woodward's 1952 formal synthesis of steroids employing an early-stage DA reaction

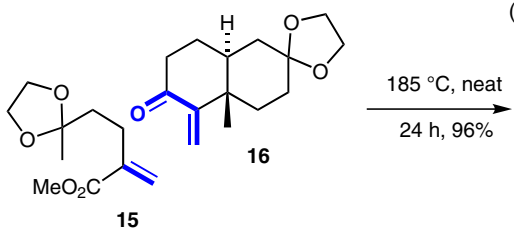

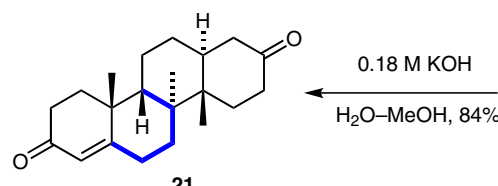
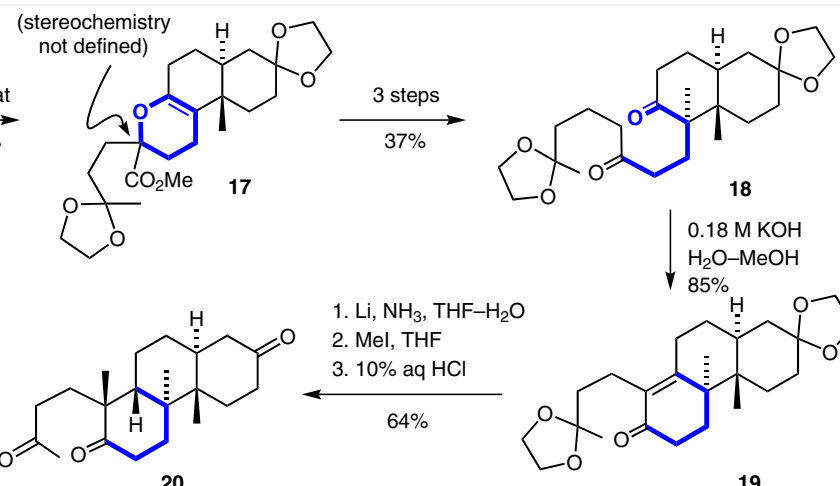

1. $\mathrm{Li}, \mathrm{NH}_{3}, \mathrm{THF}-\mathrm{H}_{2} \mathrm{O}$

2. Mel, THF

3. $10 \%$ aq HCl

$64 \%$

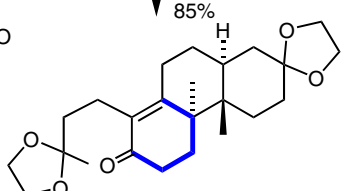

19

Scheme 3 Ireland's 1977 approach to the fusidic acid skeleton employing a hetero-DA reaction 
ported and this product forms by way of a transition-state structure with a boat-like tether conformation, TS-25. The DA event thus sets up the correct stereochemistry at the quaternary C10 stereocenter, with the configuration at C9 being epimerized later. DA adduct 25 was ozonolyzed to $\mathbf{2 6}$, cleaving the newly formed cyclohexene ring and introducing the requisite ketone functionality at $\mathrm{C} 11$. This reaction also liberates the necessary side chain for the ubiquitous intramolecular aldol condensation to form the A-ring. This last step proceeded with epimerization at C9 to give adrenosterone. The conversion of bicycle $\mathbf{2 2}$ into adrenosterone is striking in its step economy, the result of a sequence of exquisitely well orchestrated reactions. Cyclization of the tether connecting the diene and dienophile in the key DA reaction results in the formation of the B-ring of the natural product. The Stork research group prepared progesterone in 1982 in a similar manner. ${ }^{11}$

A fourth example of the strategic use of the DA reaction to construct a 'non-skeletal' ring is illustrated in Rao's 1991 formal synthesis of estrone (Scheme 5). ${ }^{12,13}$ The starting material for this synthesis was the DA adduct of 1-methoxy-4-methyl-1,3-cyclohexadiene and acrolein, bridged bicycle 28. Addition of Grignard reagent $\mathbf{2 7}$ to aldehyde $\mathbf{2 8}$ followed by alcohol oxidation provided ketone 29. An acidpromoted retro-aldol elimination and hydrolysis gave cyclohexenone 30, now primed for cyclization. Thus, basemediated intramolecular Michael addition followed by acid-catalyzed intramolecular Friedel-Crafts reaction and dehydration gave tetracycle 31. D-Homosteroid 31 was converted into tricycle $\mathbf{3 2}$ over five steps, intercepting Johnson's 1957 synthesis of estrone. ${ }^{14}$

Applying chemistry originally developed by Neef and co-workers in $1989,{ }^{15}$ Grieco used a hetero-DA reaction to introduce the C14 hydroxyl group in his 1991 semi-synthesis of withanolide $\mathrm{E}$ (Scheme 6). ${ }^{16}$ Cyclopentadiene 34 was prepared in three steps from readily accessible steroid $33 .{ }^{17}$ A hetero-DA reaction with benzyl nitrosoformate at ambient temperature gave a mixture of diastereomeric DA adducts 35 and $36(\mathrm{dr}=1: 2)$. Upon heating in toluene, the minor adduct 35 was funneled through to the thermodynamically favored diastereomer $\mathbf{3 6}$. The newly formed oxazine ring was cleaved through hydrogenolysis, and subsequent hydrolysis gave the trihydroxy steroid 37. A further 15 steps completed the synthesis of withanolide E. This synthesis is unique in that it uses the DA reaction not for the installation of the carbon framework, but to impart functionality onto the core (specifically, the C14-hydroxyl group).

A final example of the formation of a 'non-skeletal' ring by way of a DA reaction is Jacobi's 2012 construction of the viridin core (Scheme 7). ${ }^{18}$ An IMDA reaction between the oxazole and alkyne groups of precursor $\mathbf{3 8}$ gave DA adduct 39, which underwent a retro-DA reaction in situ to give tetracycle $\mathbf{4 0}$ as an inconsequential mixture of geometrical isomers with varying degrees of unsaturation, presumably due to autoxidation. Overall, this sequence introduced the
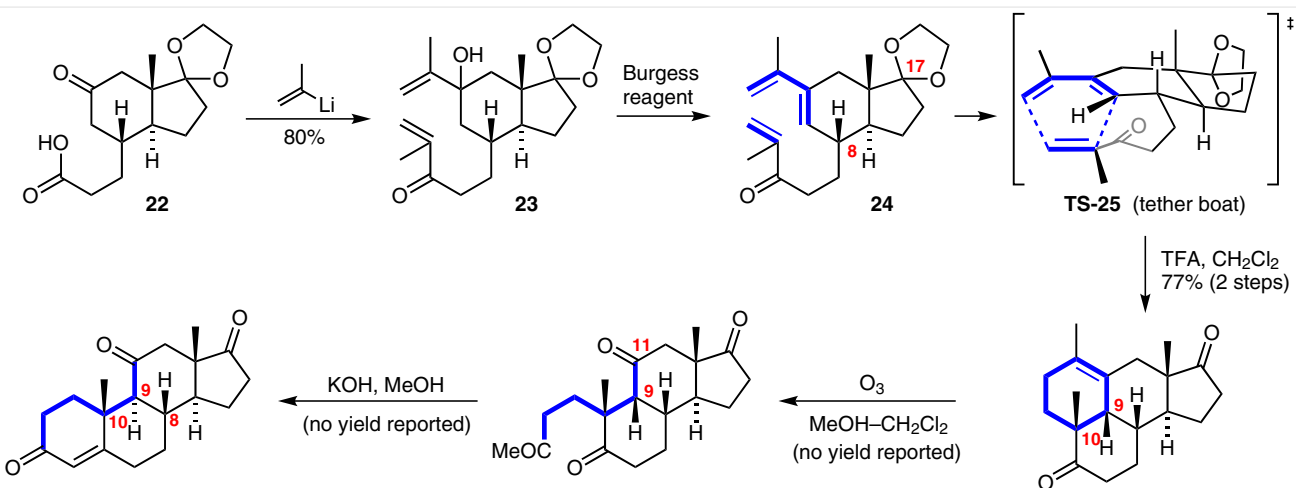

adrenosterone

26

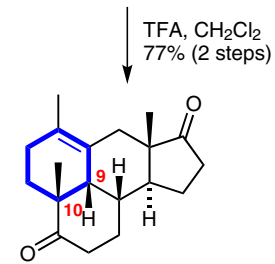

25

Scheme 4 Stork's 1987 synthesis of adrenosterone featuring an IMDA reaction
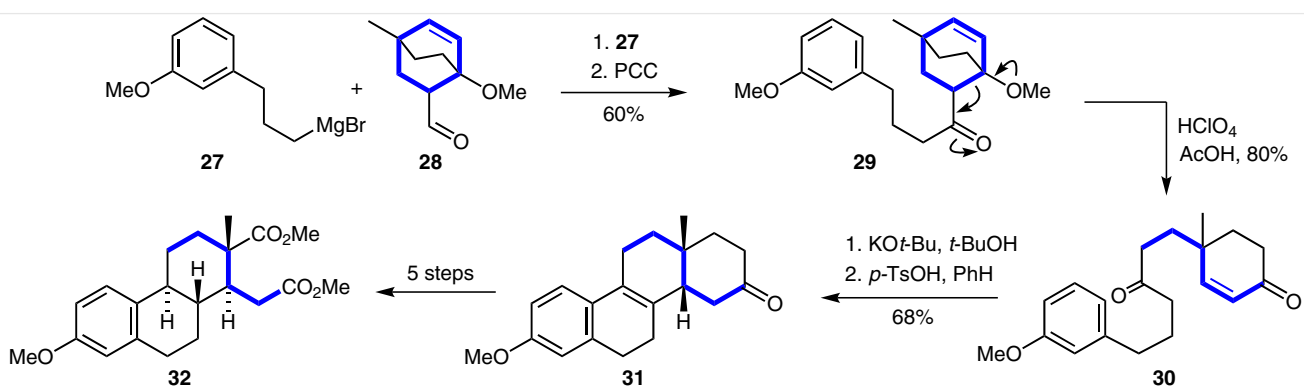

Scheme 5 Rao's 1991 formal synthesis of estrone 
<smiles>CC(=O)OC1CC2=CCC3C4CCC(=O)[C@@]4(C)CCC3[C@@]2(C)[C@H](O)C1</smiles>

33

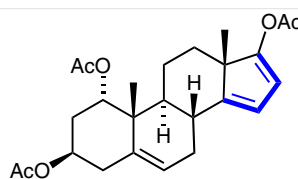

34

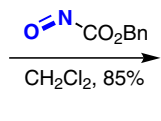

$\frac{\text { 1. } \mathrm{H}_{2}, \mathrm{Pd} \cdot \mathrm{BaSO}_{4}}{2 . \mathrm{CuCl}_{2} \cdot 2 \mathrm{H}_{2} \mathrm{O}}$

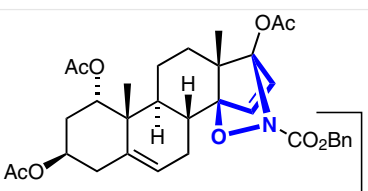

35

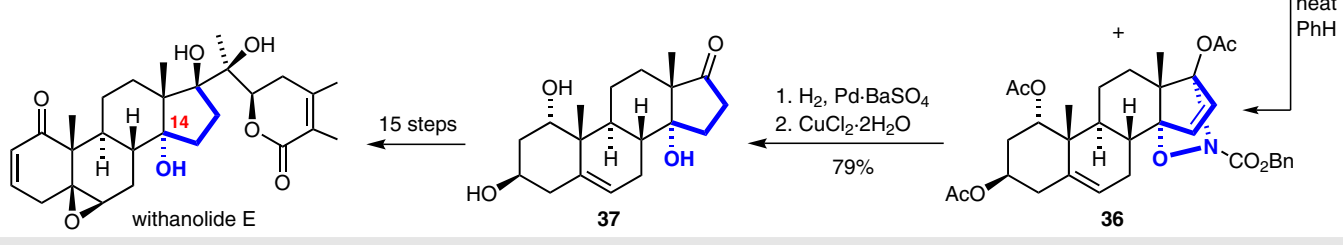

Scheme 6 Grieco's 1991 semisynthesis of withanolide E featuring a nitroso-DA reaction

furan E-ring of viridin through the cycloaddition event and the carbocyclic B-ring indirectly. A further three steps were employed to access aldehyde 41, allowing for a titanium(IV) chloride catalyzed Mukaiyama aldol-type cyclization to form the A-ring. Alcohol $\mathbf{4 2}$ was formed as the major diastereomer in $60 \%$ yield. The minor isomer, exhibiting an anti relationship between the hydroxyl and methyl groups, was isolated in $12 \%$ yield.<smiles>CCOC(=O)C=CCCCCCCCC(C)c1ccc2c(c1C(=O)c1cnco1)CCC2</smiles>

38

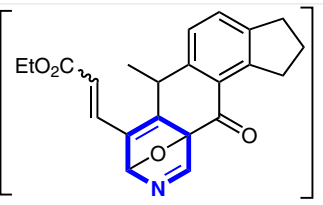

39

$\downarrow-\mathrm{HCN}$

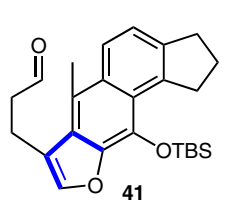

1. $\mathrm{Pd} / \mathrm{C}, \mathrm{H}_{2}, \mathrm{EtOAc}$ 2. TBSOTf, $\mathrm{Et}_{3} \mathrm{~N}$ 3. DIBAL-H, $\mathrm{CH}_{2} \mathrm{Cl}_{2}$ $55 \%$ (4 steps)

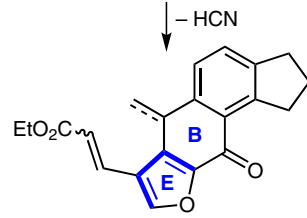

40<smiles>C[C@@]12c3ccc4c(c3C(=O)c3occ(c31)CC[C@H]2O)CCC4</smiles>
42

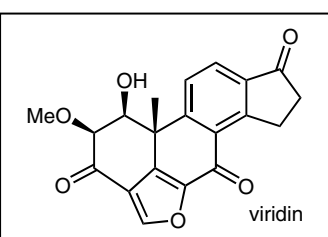

viridin
Scheme 7 Jacobi's 2012 work towards viridin featuring an IMDA-retroDA sequence

The syntheses presented in this first category of nonskeletal reactions demonstrate the versatility of the venerable DA reaction in the construction of the steroid skeleton. These cases, however, reflect only a small sample of the true diversity - and power - of the DA reaction in steroid synthesis. We now move on to the direct applications of such processes.

\subsection{Construction of the A-Ring}

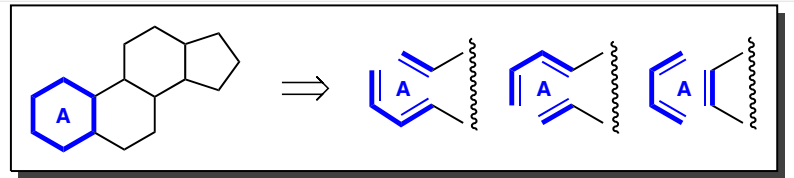

Scheme 8 A-ring disconnections reported so far

Of the six possible DA disconnections that can be performed on the steroid A-ring, only three (Scheme 8 ) have been realized synthetically. The first example was reported in Fukumoto's 1985 formal synthesis of androsterone (Scheme 9). ${ }^{19}$ The Hajos-Parrish ketone derived bicycle $\mathbf{4 3}^{20}$ was converted in 12 steps into aldehyde 44, and an E-selective olefination reaction provided the DA precursor 45 . The IMDA reaction was performed in toluene at $220^{\circ} \mathrm{C}$ in a sealed tube. These rather harsh reaction conditions reflect the unactivated nature of the dienophile. Nevertheless, a 4:1 mixture of two of the four possible diastereomeric DA adducts was obtained in a yield reported as quantitative. The stereochemical outcome of this reaction is presumably controlled by the configuration of the stereocenters at C8 and C9, placing the dienophile on the lower face of the diene as shown. The major product, namely the C5,C10-transC10,C9-anti isomer $\mathbf{4 6}$ results from a chair-like conformation of the tether (TS-46).

Acid hydrolysis of the methoxymethyl ether followed by chromium(VI) oxide oxidation of the resulting alcohol gave tetracycle 47, thus completing the formal synthesis of androsterone. ${ }^{21}$ In 1986, Fukumoto extended this method to the total synthesis of both testosterone and androsterone. ${ }^{22}$ The same DA disconnection is seen in Kobayashi's 2009 approach towards norzoanthamine. ${ }^{23}$

A similar strategy can be identified in Yang's 2011 formal synthesis of the cortistatins, albeit to form the $6,7,6,5$ tetracyclic framework. ${ }^{24}$ In this approach, the diene was a furan, and the dienophile an alkyne. IMDA precursor 49 was prepared in seven steps from a familiar bicycle $\mathbf{4 8}^{25}$ (Scheme 10). When treated with 1.5 molar equivalents of ethylaluminum dichloride, precursor $\mathbf{4 9}$ underwent IMDA 
<smiles>CCCCC1CCC2=CC(=O)CCC21C</smiles>

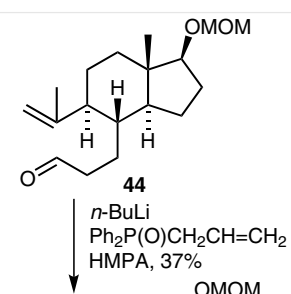

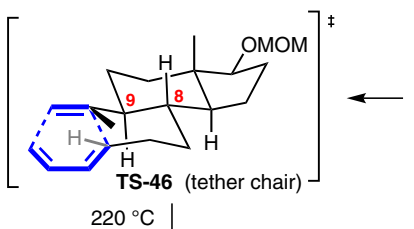

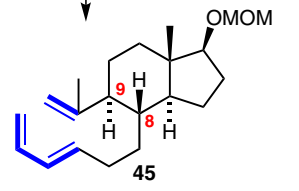
toluene, $80 \%$

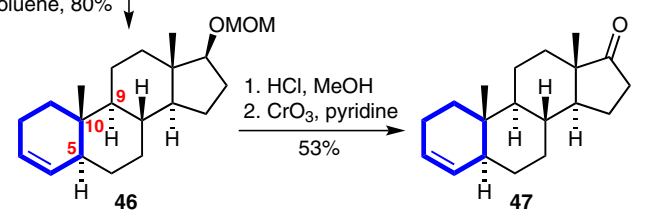

Scheme 9 Fukumoto's 1985 IMDA-based formal synthesis of androsterone

reaction to generate putative adduct $\mathbf{5 0}$, which underwent aromatization to give phenol $\mathbf{5 1}$ in 51\% yield. In addition to forming the A- and B-rings, the sequence neatly incorporated the requisite oxygen functionality at $\mathrm{C} 2$. A further eight steps were employed to access enone $\mathbf{5 2}$ and intercept Myers's 2010 synthesis of cortistatins A, J, K and L. ${ }^{26}$
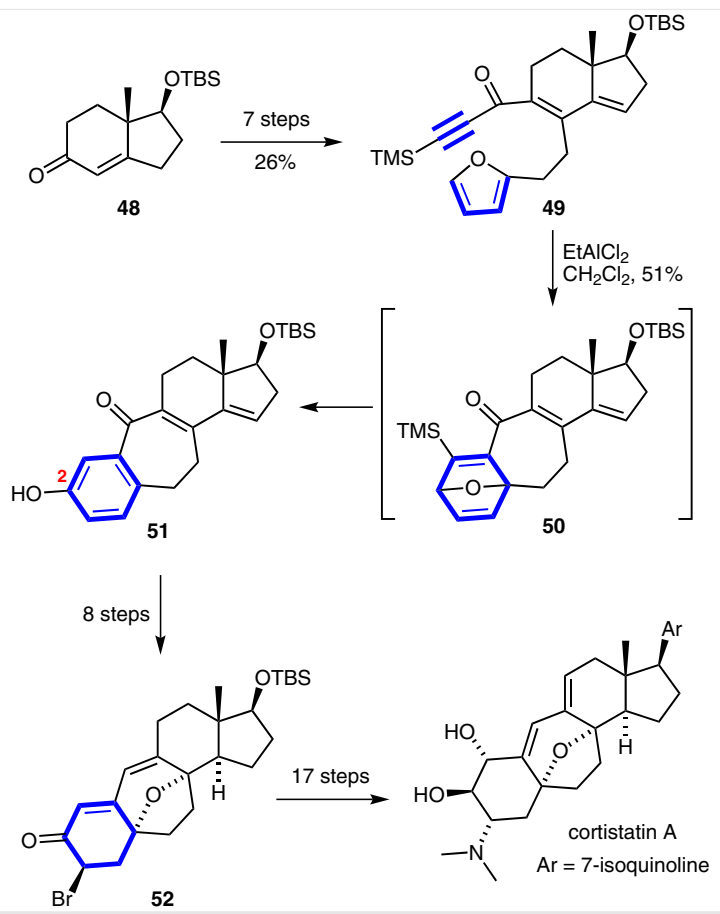

Scheme 10 Yang's 2011 formal synthesis of cortistatins A, J, K and L featuring an IMDA reaction
Transposition of the diene and dienophile gives a different DA reaction, which can be seen in Uguen's 2002 work towards the brassinosteroids ${ }^{27}$ [compare diene and dienophile locations in 45 (Scheme 9) vs. 54 (Scheme 11)]. Starting from known acid $\mathbf{5 3},{ }^{28}$ this approach featured a radical cyclization in the preparation of IMDA precursor 54 . The DA reaction was performed in a sealed tube at $145^{\circ} \mathrm{C}$, with no yield reported for the transformation, and the stereochemistry of product $\mathbf{5 5}$ was not defined. Nonetheless, the conversion $\mathbf{5 4} \rightarrow \mathbf{5 5}$ demonstrates that an IMDA reaction involving a diene carrying an inside methyl group is a viable route to the steroid skeleton carrying an angular methyl group at the $\mathrm{AB}$-ring junction.
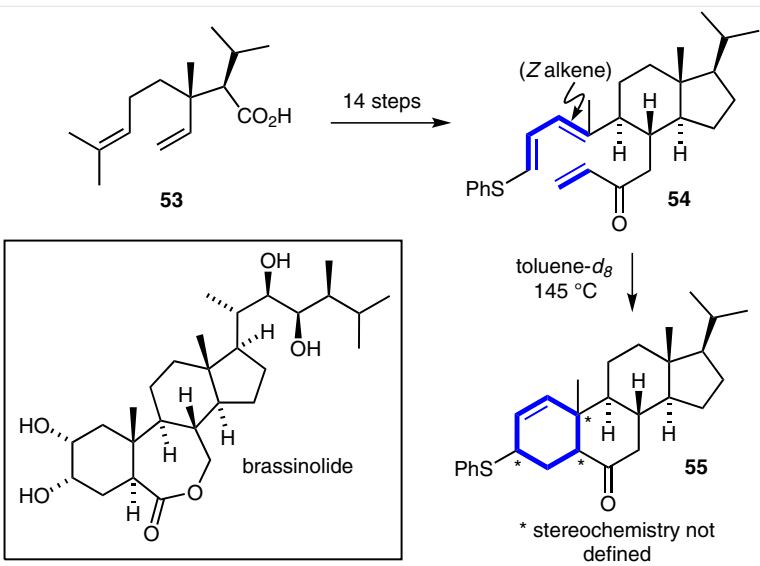

Scheme 11 Uguen's 2002 IMDA-based route to brassinosteroids

Another DA-based approach to the formation of the Aring, this time intermolecular, is illustrated in Scheme 12. In this example by Wulff and co-workers, a DA reaction between Danishefsky's diene and carbenoid $\mathbf{5 6}$ gave protected phenol 57, which underwent annulation to give tetracyclic products 58 and 59. ${ }^{29}$ This remarkable transformation has also been performed in a one-pot operation, ${ }^{30}$ making it our first example of a $0 \rightarrow A B C D$ process, namely a one-pot synthesis of the steroid framework from acyclic precursors. While the location of unsaturation (specifically the aromatic C-ring) is not ideal for a total synthesis application, this is nonetheless an interesting and efficient approach, with significant untapped potential.

Of the steroid syntheses that involve DA reactions, fewer examples generate the A-ring than the B- or C-rings. This is attributable to the fact that a disconnection of either the $\mathrm{B}$ or C-ring represents a more even division of the tetracyclic system, thereby leading to a more convergent synthesis. 


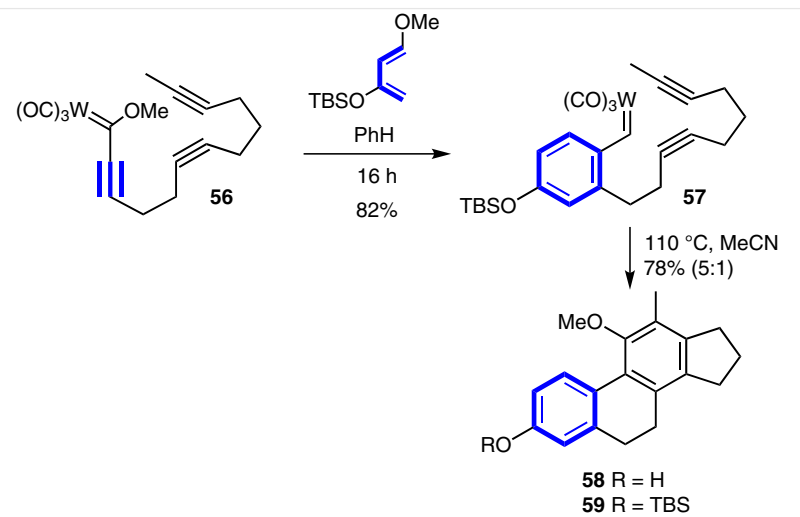

Scheme 12 Wulff's 1991 DA-double intramolecular two alkyne annulation approach to the steroid skeleton

\subsection{Construction of the B-Ring}

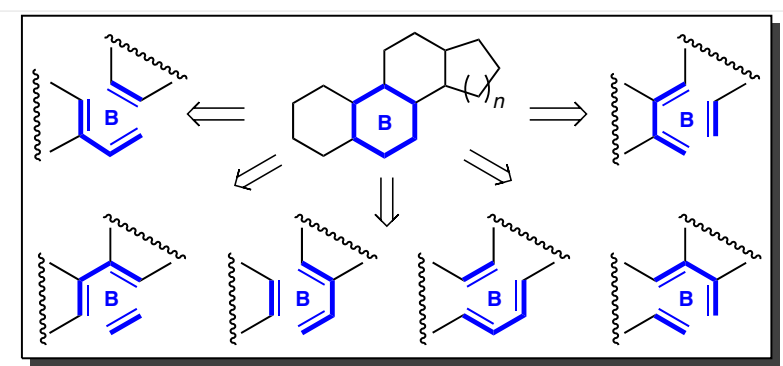

Scheme 13 B-ring disconnections reported so far

Interestingly, every one of the six conceivable DA disconnections of the steroid B-ring (Scheme 13) has been investigated experimentally. The first example is Soto's 1962 work with bicyclic diene 60, which engaged in a DA reaction with benzoquinone to form endo adduct 61 (Scheme
14). ${ }^{31}$ This general approach has been used many times since, both in the preparation of analogues ${ }^{32-35}$ and in natural product total synthesis. ${ }^{36-38}$

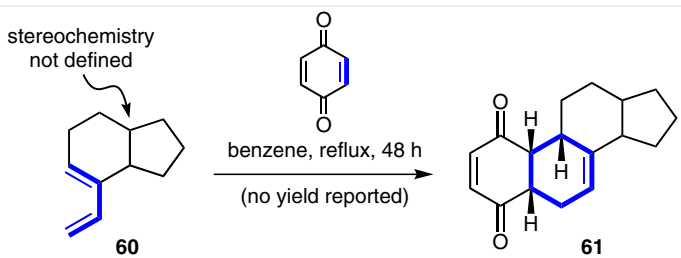

Scheme 14 Soto's 1962 DA approach to the steroid skeleton

An example of the use of this DA disconnection in total synthesis is the 2000 publication on the preparation of the nicandrenones by Corey and Stoltz, ${ }^{38}$ which featured an unusual exo-selective DA reaction between enol ether $\mathbf{6 3}$ and enantiopure enone $\mathbf{6 2}$ (Scheme 15). The dienophile's bulky dimethylphenylsilyl substituent steers the diene away from its top face. Steric interactions between substituents on the diene in the cisoid form lead to a nonplanar conformation, which disfavors endo-mode transition states. ${ }^{39}$ These features combine to favor TS-64, which leads to exo adduct 64.

The same general type of DA reaction was employed in Banwell's DA-oxy-Cope approach to the steroid skeleton. ${ }^{40}$ Thus, the DA reaction between enantiopure diene 65 (accessed by microbial dihydroxylation of bromobenzene, followed by acetal formation) and p-benzoquinone (66) was induced by mild heating (Scheme 16). The bulky ketal substituent on the diene controls $\pi$-diastereofacial selectivity, and the DA reaction proceeds via the endo mode, giving the bridged adduct 67 . A further eight steps were required to access diene 68, which after deprotonation to 69 underwent an anionic oxy-Cope rearrangement, followed by loss of methanol, to give the tetracyclic product $\mathbf{7 0 .}$

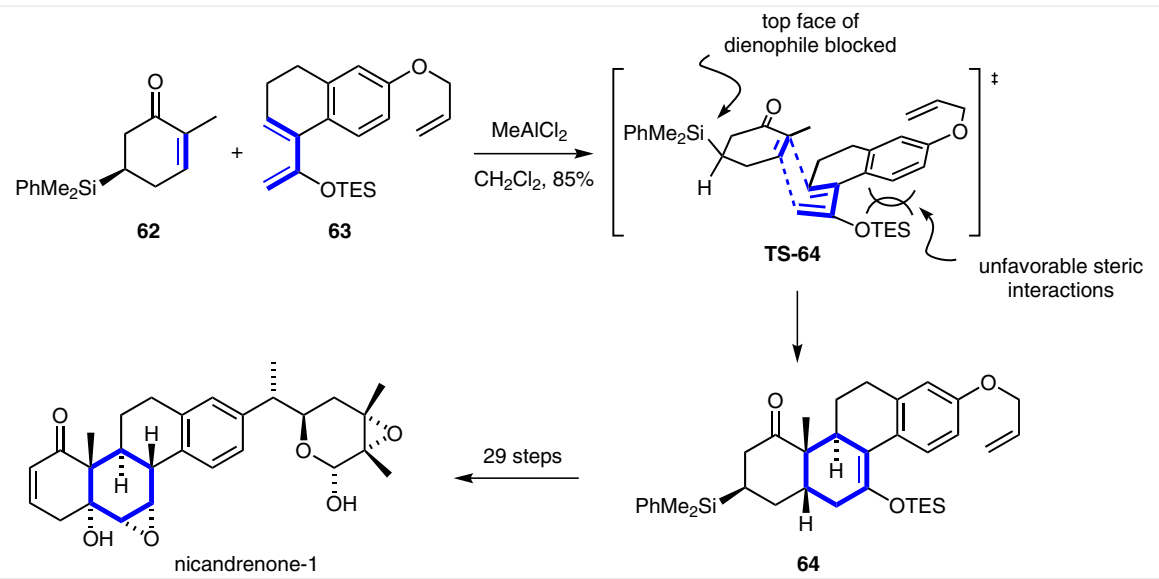

Scheme 15 Corey and Stoltz's 2000 synthesis of the nicandrenones 
<smiles>BrC1=CC=C[C@@H]2OC3(CCCC3)O[C@H]12</smiles>

65<smiles>O=C1C=CC(=O)C(C(=O)[181I])=C1</smiles>
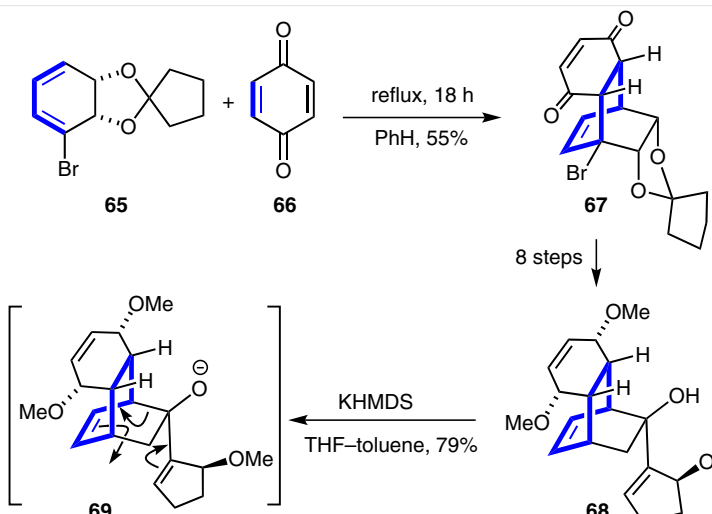
$\mathrm{H}_{3} \mathrm{O}^{\oplus}$ $-\mathrm{MeOH}$

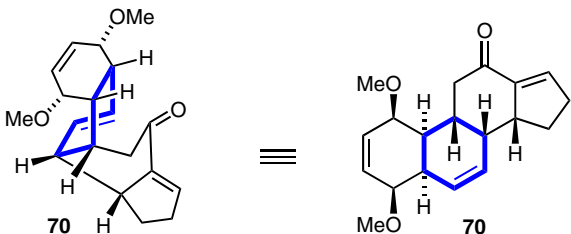

Scheme 16 Banwell's 1999 DA-oxy-Cope approach to the steroid skeleton

A different steroid B-ring-forming DA reaction was employed by the de Meijere research group in 2008 (Scheme 17). ${ }^{41,42}$ A heat-promoted DA reaction between diene 73 generated via a Stille coupling between enol triflate $\mathbf{7 1}$ and alkenyl stannane $\mathbf{7 2}$ - and dimethyl acetylenedicarboxylate (DMAD) as dienophile gave tetracycle $\mathbf{7 4}$ in good yield. The dienophile approaches diene $\mathbf{7 3}$ from the opposite face to the methyl and tert-butyloxy substituents. The DA reaction was also performed with a range of other dienophiles, including maleic anhydride, $N$-methylmaleimide (NMM) and 1,2-dicyanoethylene, to give a range of modified steroid frameworks. This DA approach was originally identified and employed in the preparation of pentacyclic steroids by Granja, using a bicyclic diene generated by dienyne ringclosing metathesis. ${ }^{43}$

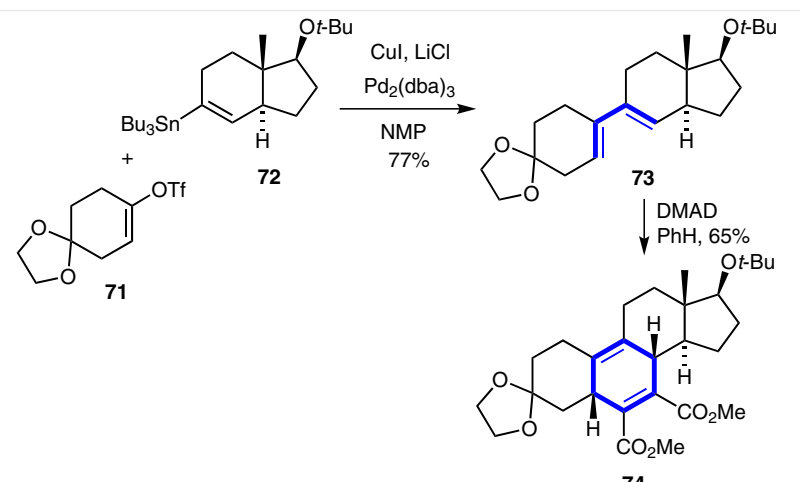

Scheme 17 de Meijere's 2008 approach to the steroid skeleton
Jung and Lui reported a third type of DA approach to the B-ring in their 2010 synthetic study towards the cucurbitacins $^{44}$ (Scheme 18), involving a semicyclic diene located on the A-ring fragment, with the $\mathrm{CD}$-ring fragment containing the dienophile. Diene $\mathbf{7 5}$ was prepared in only three steps from a known diketone, ${ }^{45}$ while dienophile 76 required a more lengthy 15 -step synthesis. The DA reaction proceeded in excellent yield under microwave heating, providing the endo adduct $\mathbf{7 7}$ (with respect to the aldehyde activating group), and completing the formation of the carbocyclic skeleton of the steroid natural product. The investigators had hoped that the diene would approach the dienophile from the opposite face to the methyl substituent, but only the unwanted diastereomer $\mathbf{7 7}$ was observed, indicating that the proximal cyclopropyl ring likely controls the $\pi$-diastereofacial selectivity of the reaction.

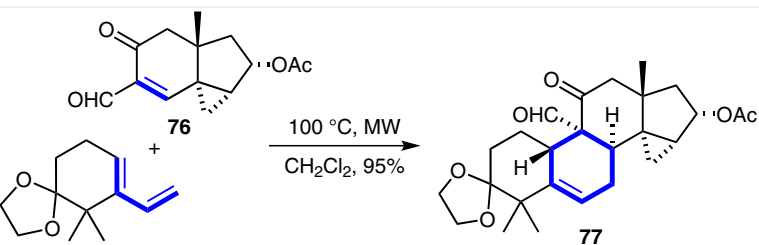

75

Scheme 18 Jung and Lui's 2010 convergent DA approach towards the cucurbitacins

A different type of DA disconnection involving a furan diene can be identified in De Clercq's 1983 synthesis of 11ketotestosterone. ${ }^{46}$ The IMDA reaction of precursor 78 proceeded in water by way of tether boat conformation TS-79, generating exo adduct 79 (Scheme 19). The DA reaction proved reversible in organic solvents, but the target DA adduct 79 could be trapped as reduced cycloadduct 80 by hydrogenation. This intermediate was elaborated over several steps to chloroalkene $\mathbf{8 2}$, allowing for the final cyclization (through hydrolysis to the methyl ketone and intramolecular aldol condensation) to 11-ketotestosterone in 65\% yield. De Clercq used a similar approach, this time with an alkynic dienophile, in his 1985 synthesis of D-homo epi-adrenosterone. $^{47}$

A furan-diene also featured in Friedrichsen's 1988 isobenzofuran approach to the 11-oxasteroid skeleton. ${ }^{48}$ In this example, the transient isobenzofuran 84 was generated from diazo ester $\mathbf{8 3}$ by treatment with $\mathrm{Cu}$ (hfac) (Scheme 20). The IMDA reaction occurred in situ, and was followed by an elimination reaction of adduct $\mathbf{8 5}$ to give enol ether 86 in excellent yield. 

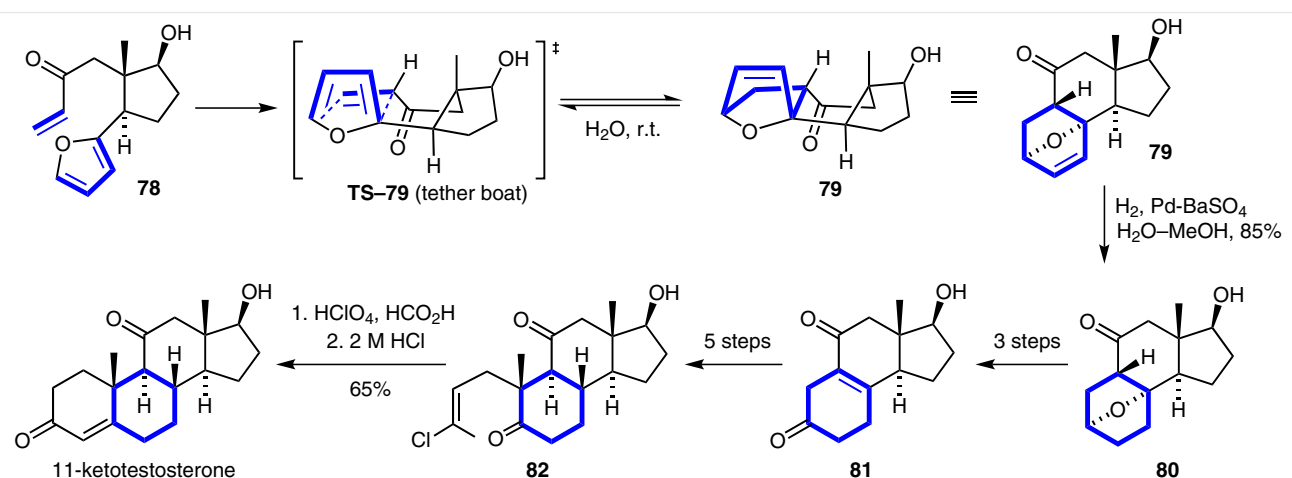

Scheme 19 De Clercq's 1983 furan-diene IMDA approach to the steroid skeleton<smiles>C=CC1CCC2(OCCO2)C1(C)COC(=O)c1ccc(OC)cc1C(=O)C(C)=O</smiles><smiles>COc1ccc2c(c1)[C@](O)(C(C)=O)CC1=C2OCC2(C)C1OCC1(C)C2CCC12OCCO2</smiles>

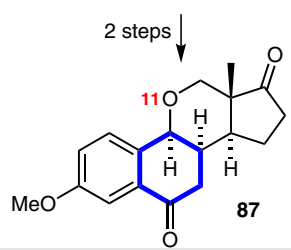

Scheme 20 Freiderichsen's 1988 isobenzofuran IMDA approach to the 11-oxasteroid skeleton

The stereochemistry at $\mathrm{C} 13$ and $\mathrm{C} 14$ places the diene below the dienophile during the cycloaddition. This, coupled with the exo-mode cycloaddition, results in the observed configuration at $\mathrm{C} 6$ in the final product $\mathbf{8 6}$. A further two steps gave the diketone 87. A similar strategy is seen in Herndon's 2001 approach to the all-carbon steroid skeleton, forming the transient isobenzofuran diene in situ in a convergent manner from two building blocks. ${ }^{49}$

The same general DA disconnection, realized synthetically in a very different manner, is seen on analysis of Tietze's synthesis of a range of heterosteroids. ${ }^{50} \mathrm{~A}$ representative example is depicted in Scheme 21, in which ketone 89 underwent a Knoevenagel condensation with diamide $\mathbf{8 8}$ to generate the intermediate enone $\mathbf{9 0}$. An in situ heterodiene-IMDA reaction provided the tetracyclic DA adducts 91 as a 2:1 mixture of diastereomers. This mixture of diastereomers presumably arises from an epimerization of the benzylic stereocenter following the cycloaddition. The reaction proceeded via the endo mode (with respect to the phenyl group), through a tether chair conformation (TS-91), with dienophile approach from the top face of the diene. This is an efficient way to construct the tetracyclic skeleton of steroid-like structures. Its application in the total synthesis of a natural product has not yet been reported.

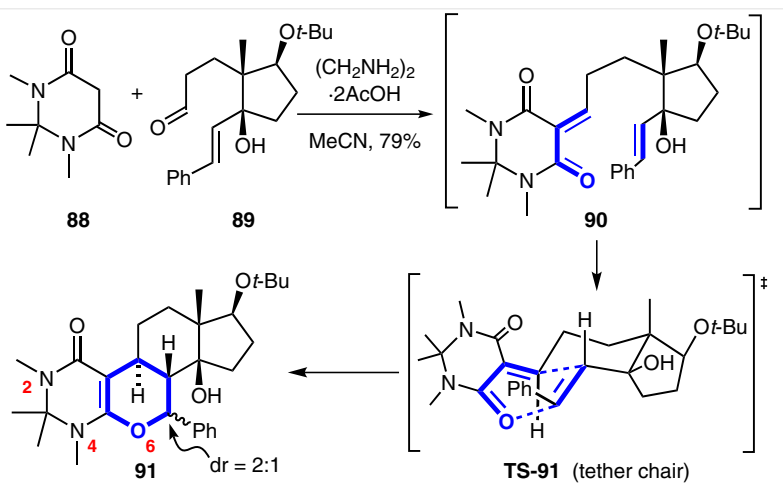

Scheme 21 Tietze's 1990 Knoevenagel-IMDA approach to the 2,4-diaza-6-oxasteroid framework

A different strategic application of the same DA disconnection is illustrated in two publications by Bleasdale and Jones. ${ }^{51,52}$ Thus, formation of the benzopyran diene $\mathbf{9 3}$ was effected from precursor 92 in refluxing acetic anhydride (Scheme 22). This reactive 0 -quinone dimethide-type diene intermediate underwent a regioselective intermolecular DA reaction with unactivated dienophile 94 , to give ester 95 as a mixture of all four possible diastereomers. This mixture of four diastereomers (ratio not specified) was simplified to two by isomerization later in the synthesis. Elaboration of cycloadduct 95 into diester 96 allowed for a Dieckmann cyclization, which completed the construction of the tetracyclic framework. This synthesis is another good example of how the DA reaction can bring about rapid and convergent access to the steroid skeleton. 
<smiles>O=Cc1ccccc1CC(=O)O</smiles>

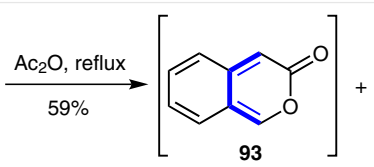<smiles>C=CC1CCC(=O)C1(CC(C)=O)CC(C)=O</smiles>

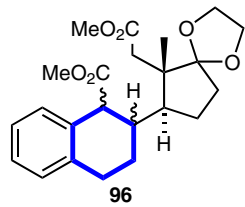
$\mathrm{NaH}$ $\mathrm{MeOH}-\mathrm{THF}$

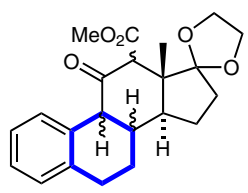

97

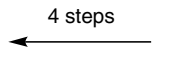

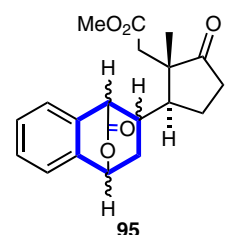

4 steps

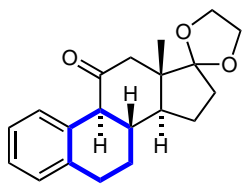

98
Scheme 22 Bleasdale and Jones's 1985 benzopyran DA approach to the A-ring aromatic steroid skeleton

Perhaps the most well known application of the DA reaction in aromatic steroid synthesis involves firstly an electrocyclic ring opening of a benzocyclobutene followed by intramolecular DA reaction. The first example of this approach was Kametani's formal synthesis of estrone, reported in 1976 (Scheme 23). ${ }^{53,54}$ Benzocyclobutene 101 was prepared via alkylation of the potassium enolate of ketone $\mathbf{1 0 0}$ with iodide 99. Retro-aldol condensation removed the exocyclic thiomethylene group to furnish the precursor for the key step of the synthesis. Under thermal conditions, benzocyclobutene 102 underwent a $4 \pi$-electrocyclic ring opening, generating 0 -quinone dimethide 103 , which underwent the IMDA reaction in situ, via tether chair conformation TS-104, to give the exo adduct 104 in a highly diastereoselective fashion and in excellent yield.
The importance of Kametani's contribution - and the value of the benzocyclobutene ring opening-IMDA sequence in aromatic steroid synthesis - can be measured by the large number of subsequent syntheses that implement variations upon it. Since this inaugural publication, a wide array of steroids and steroid analogues, in both enantiopure $^{55-61}$ and racemic ${ }^{62-64}$ forms, have been accessed by this approach. Ibrahim-Ouali and Santelli have prepared thiasteroids, ${ }^{65,66}$ oxasteroids, ${ }^{67}$ azasteroids, ${ }^{68,69}$ selenasteroids, ${ }^{70}$ tellurasteroids, ${ }^{71}$ and analogues in this manner. ${ }^{72-76}$ There also exist alternative syntheses of 0 -quinone dimethides from trimethylsilyl ${ }^{77,78}$ and sulfonyl ${ }^{79,80}$ starting materials, or by way of a radical cascade. ${ }^{81}$

This last approach (which, from a retrosynthetic analysis perspective involves a different B-ring disconnection) is illustrated in Scheme 24, in which the highly unsaturated acyclic hydrocarbon precursor $\mathbf{1 0 5}$ undergoes a remarkable domino sequence to form tetracycle 110 in one pot. ${ }^{81}$ First, a thermal Myers-Saito cycloaromatization of the enynallene portion gives biradical 106. A 5-exo-trig radical cyclization gives 107 , which is followed by 1,5 -hydrogen atom transfer to generate the $\boldsymbol{o}$-quinone dimethide $(\mathbf{1 0 8} / \mathbf{1 0 9})$. The IMDA reaction completes the formation of the steroid framework, with tetracycle $\mathbf{1 1 0}$ being isolated in 50\% yield as a 2:1 mixture of epimers at $\mathrm{C} 15$. This $0 \rightarrow \mathrm{ABCD}$ approach is a remarkably efficient way to construct the steroidal nucleus.

Among the many steroid syntheses involving the benzocyclobutene ring opening-IMDA sequence, the most celebrated is Vollhardt's 1980 synthesis of estrone. ${ }^{57}$ The synthesis is striking in terms of its brevity. Over 30 years on, it still defines the high point of aromatic steroid total synthesis efforts and will no doubt remain so for many years to come. A cobalt-catalyzed $[2+2+2]$ tri-alkyne cyclization generated benzocyclobutene $\mathbf{1 1 3}$ from alkyne $\mathbf{1 1 1}$ and diyne 112. This intermediate underwent a $4 \pi$-electrocyclic ring opening to $\boldsymbol{o}$-quinone dimethide $\mathbf{1 1 4}$ followed by an IMDA reaction, to give the target exo diastereomer 115 (Scheme 25). This product is the result of tether chair conformation TS-115, with the configurations at C13 and C14

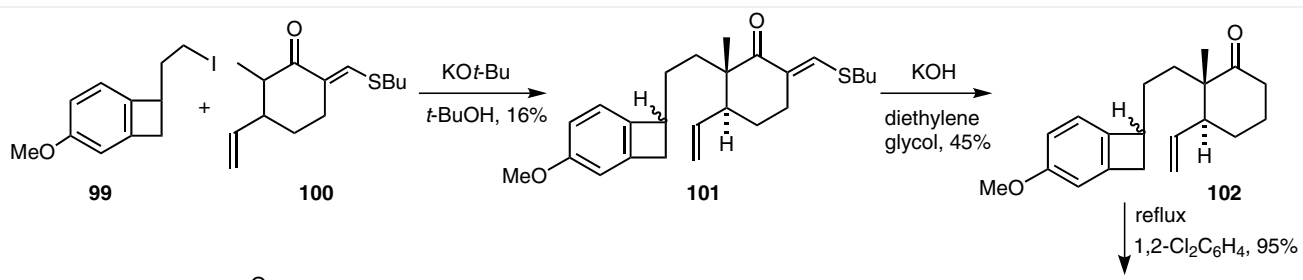<smiles>COc1ccc2c(c1)CCC1C2CCC2(C)C(=O)CCCC12</smiles>

104

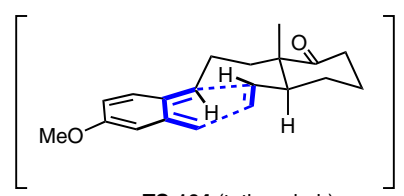

TS-104 (tether chair)
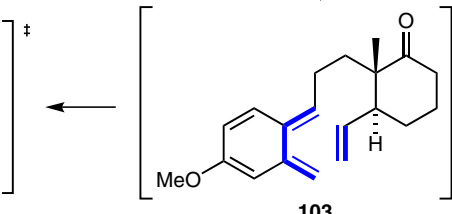

103

Scheme 23 Kametani's 1976 D-homosteroid synthesis (and formal synthesis of estrone) using a benzocyclobutene ring opening-IMDA sequence 


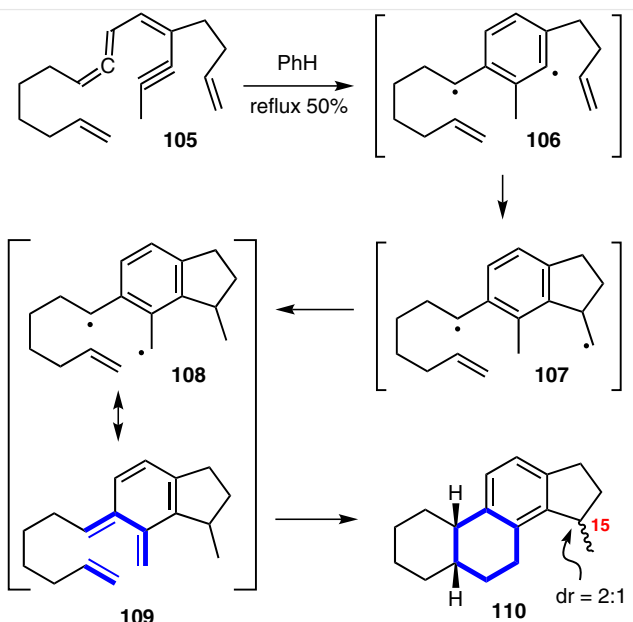

Scheme 24 The generation and IMDA reaction of ortho-quinone dimethide $108 / 109$ by a cycloaromatization-radical-cascade sequence by Wang (1993)

causing the dienophile to approach the diene from its top face and exo with respect to the bulky dienophile substituent. Thus, three of the four rings of the target structure were created in a one-pot operation, with two of the three resulting from an IMDA reaction. Only three additional steps were required to complete the total synthesis. Vollhardt has also reported a variation of this theme that allows a $0 \rightarrow A B C D$ synthesis of a steroid skeleton containing an aromatic B-ring. ${ }^{82}$

Our last example of a $\mathrm{B}$-ring-forming DA reaction in steroid synthesis is the transannular Diels-Alder (TADA) approach, pioneered by Deslongchamps. ${ }^{83-89}$ It was applied in 1988 to the synthesis of androst-6-ene-3,17-dione (121) by Takahashi $^{90}$ (Scheme 26). The unlikely looking steroid precursor 118 was prepared from iodide 116 and enone 117 as a mixture of diastereomers.

Ring closure of trisubstituted cyclopentanone 118, through deprotonation and alkylation of the protected cyanohydrin, followed by acid-mediated hydrolysis gave macrocycles 119 and 120 in good yield. Following separation of the two isomers, trans-fused diastereomer 120 underwent the TADA reaction in xylene (presumably in a sealed tube) in excellent yield and diastereoselectivity, generating the Athrough C-rings of product 121 in one step. The TADA event proceeds via chair-boat-chair conformation TS-121. This type of TADA reaction was subsequently used in the preparation of a number of steroid analogues by Deslongchamps. ${ }^{84-89}$

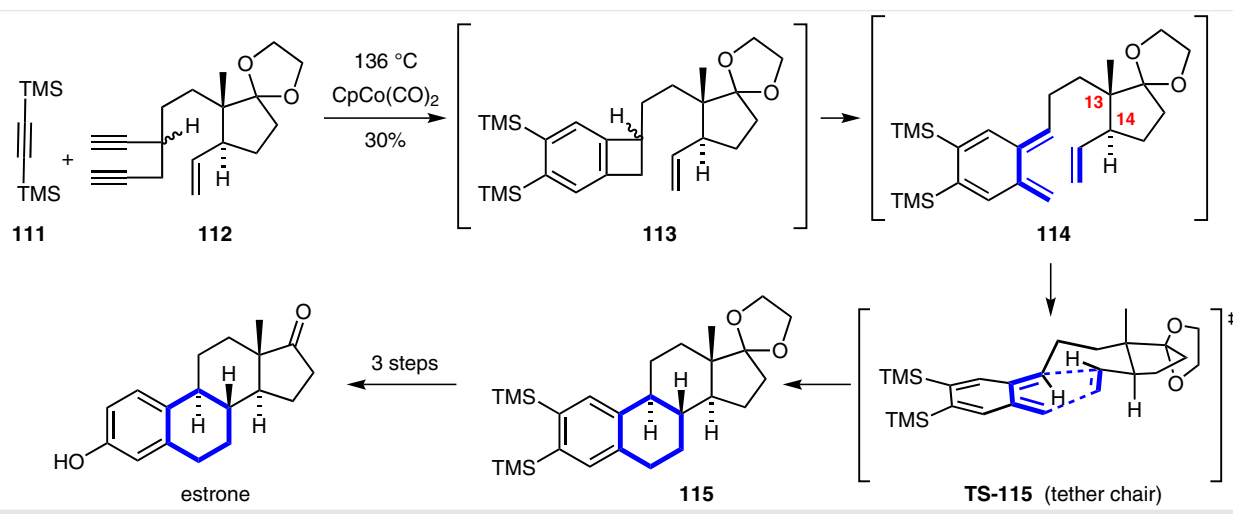

Scheme 25 Funk and Vollhardt's 1980 synthesis of estrone featuring a benzocyclobutene electrocyclic ring opening-IMDA sequence
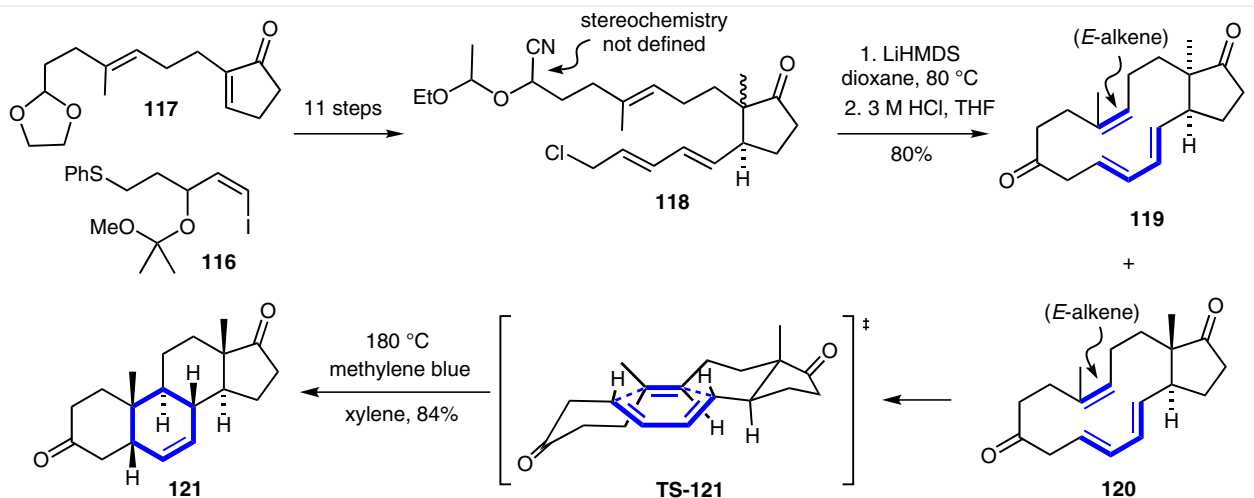

Scheme 26 Takahashi's 1988 transannular DA approach to the steroid skeleton generating the A-, B- and C-rings in one step 
This concludes our coverage of steroid B-ring forming $D A$ reactions. We move on now to the use of $D A$ reactions to form the C-ring. Due to the almost symmetrical structure of the steroid skeleton, these C-ring-forming examples closely mirror those covered in the B-ring section.

\subsection{Construction of the C-Ring}

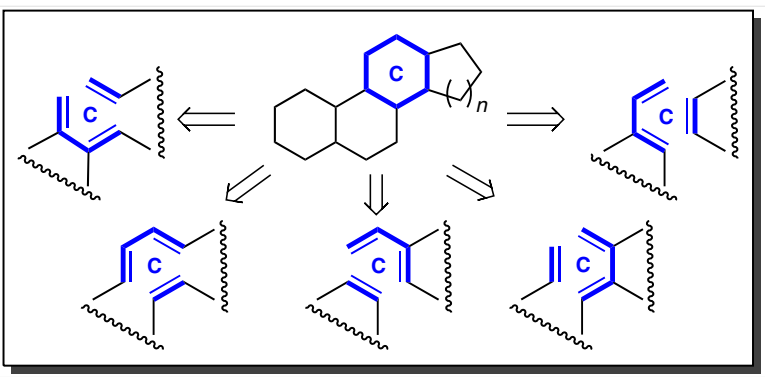

Scheme 27 C-ring disconnections reported so far

The use of a DA reaction in the direct formation of the steroid C-ring is by far the largest category covered in this review, with over 60 publications in the area. Of the six possible disconnections that can be performed on the C-ring, synthetic approaches to steroids involving five (Scheme 27) have been reported. One particularly popular tactic involves the use of a semi-cyclic diene, which was first reported by Cohen and Warren in 1937 (Scheme 1) ${ }^{4}$ and has been implemented many times since.

One landmark example of this type of DA reaction is Dane and Schmitt's use of what became known as Dane's diene $^{91}$ (122) (Scheme 28). In work presumably carried out contemporaneously with that of Cohen and Warren, Dane and Schmitt's 1938 report describes the DA reaction of diene 122 with 3-methylcyclopent-3-ene-1,2-dione. The orientational regioselectivity of this reaction was not deduced,

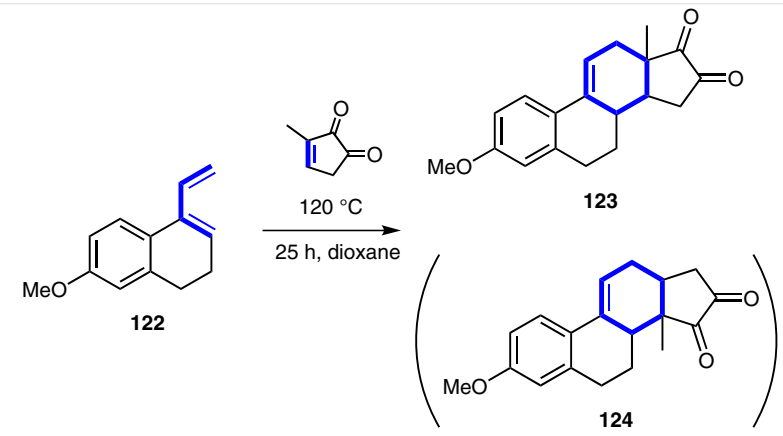

(stereochemistry not defined)

Scheme 28 Dane's diene (122) used in the construction of the steroid skeleton with an aromatic A ring (Dane and Schmitt, 1938) but the two DA cycloaddition structures 123 and 124 were proposed. This reaction was revisited by Singh in 1956, and it was revealed that regioisomer $\mathbf{1 2 3}$ is generated in this reaction, ${ }^{92}$ perhaps not surprisingly given the presence of the strongly electron-donating $p$-methoxyaryl group at $\mathrm{C} 2$ of the diene.

This type of cycloaddition has been used numerous times since, employing cyclic and acyclic dienophiles, to make aromatic ${ }^{93-99}$ and non-aromatic steroids, ${ }^{100-102}$ as well as steroid analogues. ${ }^{103-124}$ It has also been performed enantioselectively, ${ }^{125-130}$ and in an intramolecular sense. ${ }^{131,132}$

Perlmutter reported a related steroid C-ring-forming DA reaction between the dienophile 1,2-naphthoquinone (125) and semicyclic diene 126, to give endo DA adduct 127 in high diastereoselectivity $(\mathrm{dr}=20: 1)^{133}$ (Scheme 29). The $\pi$-diastereofacial selectivity of this reaction comes about through approach of the dienophile to the less sterically encumbered face of the diene.

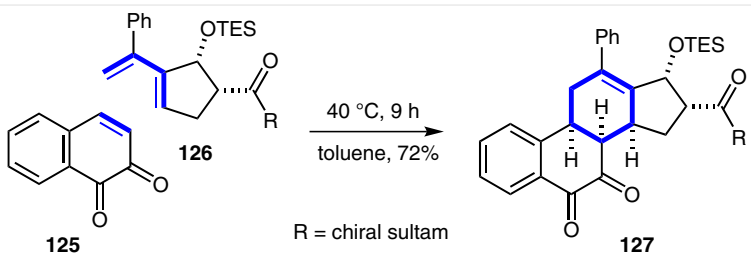

Scheme 29 Perlmutter's 2006 convergent synthesis of the steroid skeleton

A different C-ring DA disconnection can be identified by analysis of Kametani's 1983 synthesis of androstane-2,17dione $(\mathbf{1 3 0})^{134}$ (Scheme 30 ). The IMDA reaction of unactivated triene 128 was effected at $200{ }^{\circ} \mathrm{C}$ in a sealed tube, giving diketone $\mathbf{1 2 9}$ as the sole product, after acid-mediated acetal deprotection. This cycloadduct is formed via tether chair conformation TS-129, with the diene constrained to approach the top face of the dienophile and the chair conformation of the tether securing the desired trans ringjunction geometry. A shrewd application of Snider's Lewis acid mediated Prins cyclization-1,2-H shift-1,2-methyl shift sequence ${ }^{135}$ formed the D-ring and completed the synthesis of the tetracyclic steroid framework with the transanti-trans-anti-trans stereochemistry. Isomer $\mathbf{1 3 0}$ was the only product reported.

The same DA disconnection is revealed upon analysis of Tsuge's 1986 synthesis of the 15,16,17-triazasteroid nucleus, which employs the IMDA reaction of precursor $\mathbf{1 3 1}^{136}$ (Scheme 31). The carbon-carbon double bond of endo DA adduct 132 was trapped in a $[3+2]$ cycloaddition with phenyl azide to give the 15,16,17-triazasteroid skeleton 133 in $43 \%$ yield. 

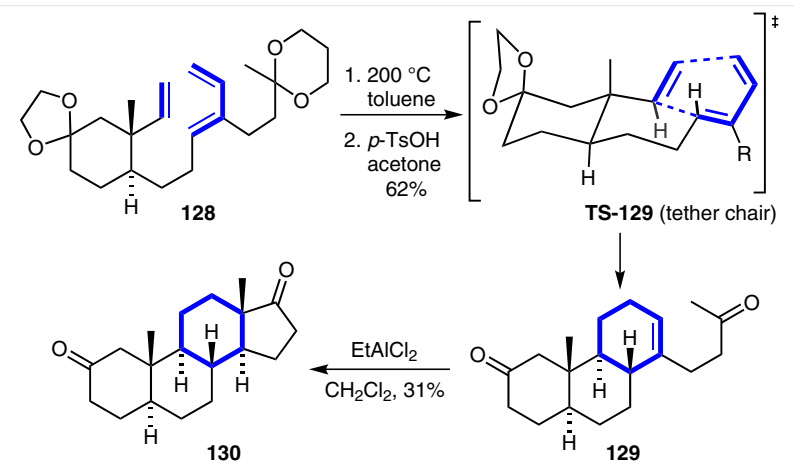

Scheme 30 Kamateni's 1983 steroid synthesis featuring an unactivated dienophile IMDA reaction to form the C-ring

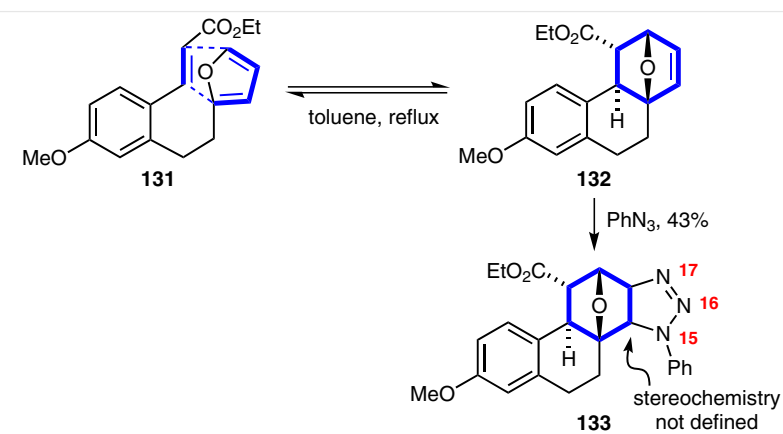

Scheme 31 Tsuge's 1986 furan-diene IMDA approach to a 15,16,17triazasteroid

The Li research group's formal synthesis of estrone ${ }^{137}$ employs a closely related but still distinct type of DA process (Scheme 32). In an approach attempted originally by Woodward, ${ }^{138}$ furan 134 underwent an endo DA reaction with the dienophile dimethyl maleate giving, after ester reduction, oxanorbornene diol 135. A Lewis acid catalyzed rearrangement gave allylic alcohol 136, which underwent an in situ intramolecular Friedel-Crafts reaction to give tricy- cle 137. A further four steps gave the chain-extended analogue 138, which was set up for an elimination-oxidationcarbocyclization sequence that ultimately provided tetracycle 139.

Another example of C-ring formation employing a furan diene is seen in Kishi's 1998 total synthesis of batrachotoxinin $A^{139}$ (Scheme 33). An intermolecular DA variant, forming the same carbon-carbon bonds, was reported by Narasimhan and Bapat in their 1984 formal synthesis of equilenin and isoequilenin. ${ }^{40}$ In the Kishi work, DA precursor 141, prepared in nine steps from ketone 140 , underwent an endo-selective IMDA reaction in situ upon oxidation to aldehyde 142. The $\pi$-diastereofacial selectivity of this reaction, in which the dienophile approaches the furan-diene from the top face (TS-143), is the result of steric shielding of the lower face by the bulky tert-butyldimethylsilyloxy group at C6. The DA adduct 143 was subjected, without purification, to a reductive amination and acetylation sequence to provide tetracycle $\mathbf{1 4 4}$. The side-chain - introduced in this sequence by manipulation of the dienophile activating group - is required for the installation of an additional ring present in the batrachotoxinin framework.

A connection can be made between Kishi's 1998 batrachotoxinin total synthesis and a 2007 synthetic methods study reported by Lu and Ma. ${ }^{141}$ These seemingly disparate examples both employ essentially the same type of IMDA reaction. In the later study, bicyclic diene 147 was generated using a rhodium-catalyzed triple-allene cyclization (Scheme 34). The dienophile was introduced via malonate alkylation, with the product undergoing an in situ IMDA reaction through TS-148. The dienophile approaches the diene from its convex face (that is, the same face as the hydrogen at C10) and through the endo mode to form IMDA adduct 148 with trans geometry at the C-D ring junction. This remarkably step-economical approach to the steroid framework awaits application in total synthesis.<smiles>COc1cccc(CCc2cccc(OC)c2)c1</smiles>

Scheme 32 Li's 2011 furan-diene approach to estrone methyl ether 139 


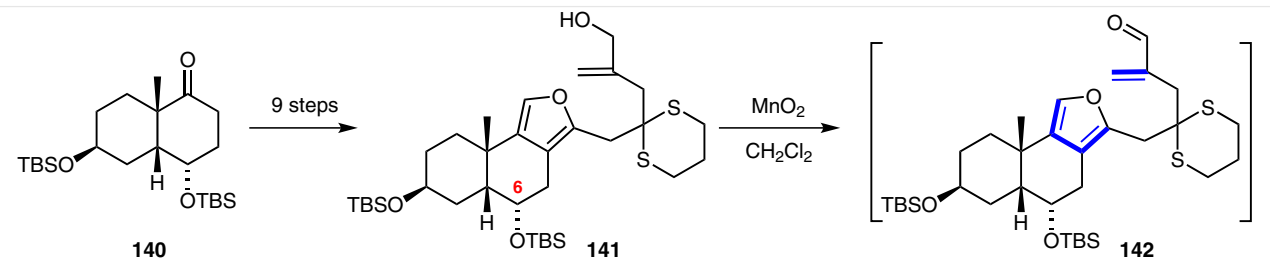

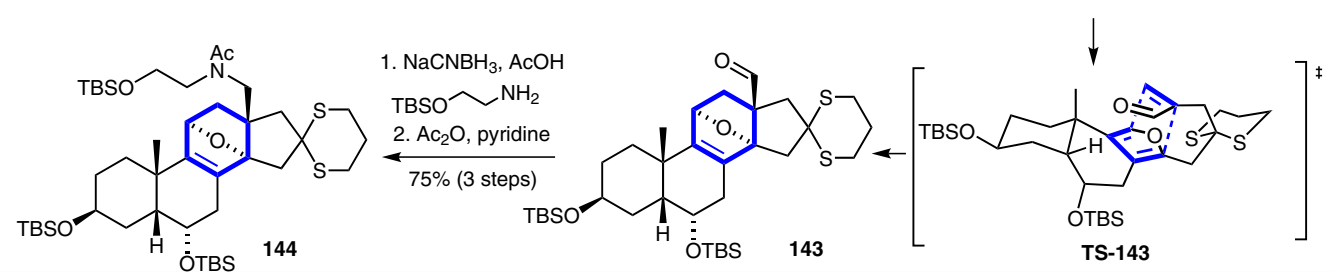

Scheme 33 The key tetracycle-forming steps in Kishi's 1998 total synthesis of batrachotoxinin A

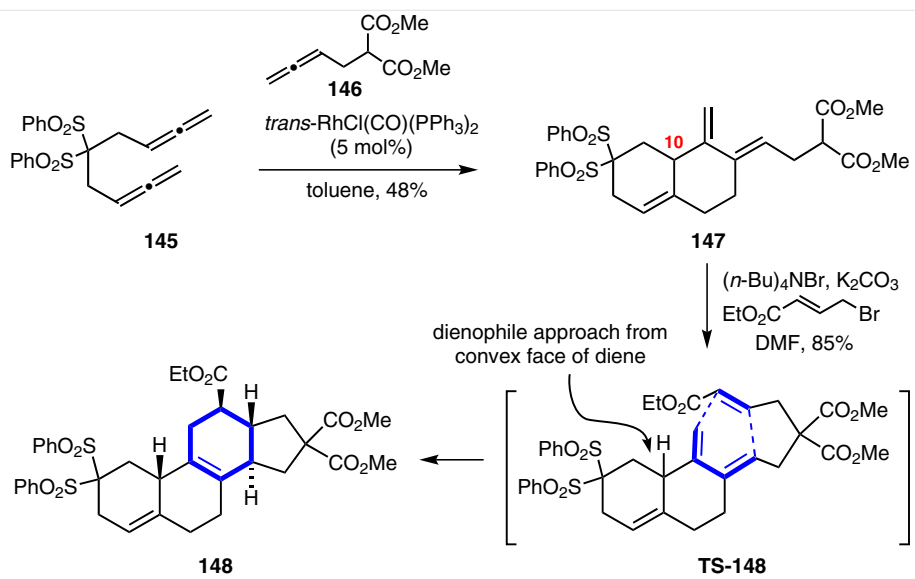

Scheme 34 Lu and Ma's 2007 approach to the steroid skeleton featuring a C-ring-forming IMDA reaction

The durable benzocyclobutene ring opening-IMDA sequence has also seen use in the construction of the steroid C-ring. The total synthesis of 9,11-dehydroprogesterone (152) by Kametani is a representative example (Scheme 35). ${ }^{142}$ The electrocyclic ring opening-IMDA reaction sequence was effected in refluxing dichlorobenzene, providing trans-fused adduct $\mathbf{1 5 1}$ as a mixture of epimers at C17 following acid-mediated acetal hydrolysis. Tricycle $\mathbf{1 5 1}$ was converted through an eight-step sequence into 9,11-dehydroprogesterone (152). A high price is thus being paid, in terms of step count, for the application of the powerful benzocyclobutene electrocyclic ring opening-IMDA sequence for the synthesis of a non-aromatic steroid target. Nevertheless, this type of IMDA reaction has been used several times in the synthesis of steroids and analogues. ${ }^{143-147}$

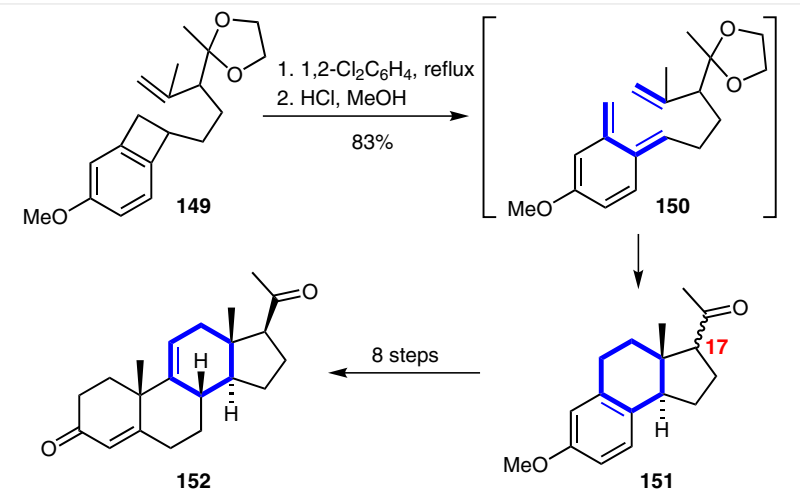

Scheme 35 The DA reaction in Kametani's 1985 synthesis of 9,11-dehydroprogesterone (152)

Deslongchamps used C-ring-forming TADA reactions in the preparation a number of functionalized steroids. ${ }^{148,149}$ The macrocyclic DA precursor 154, for example, was prepared in 14 steps from 6-methoxytetralone 153 (Scheme 36). This compound underwent an inverse-electrondemand TADA reaction in refluxing xylene to give endo adduct 155 with high diastereoselectivity. 


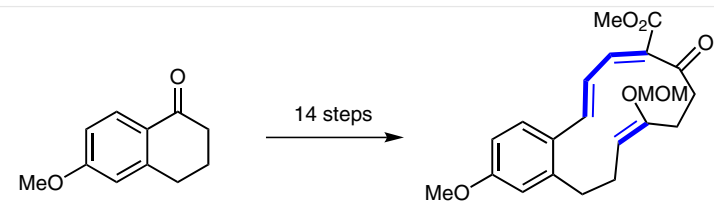

153

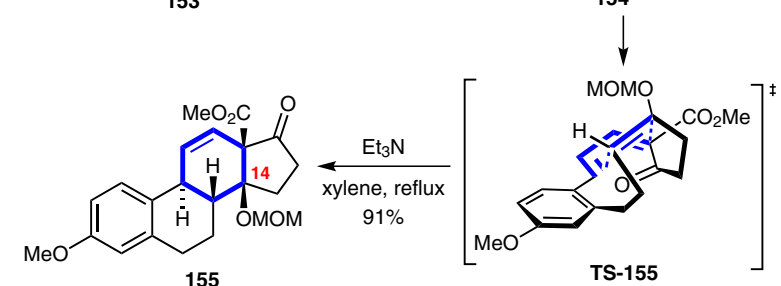

Scheme 36 Deslongchamps's 1997 transannular DA approach to 14hydroxysteroid 155, generating the B-, C- and D-rings in one step

The same DA process can be identified in Gschwend's 1973 synthesis of pentacyclic 7,16-diazasteroids ${ }^{150}$ (Scheme 37). In this case, however, the DA process was carried out intramolecularly rather than in a transannular manner. The IMDA precursor 157, formed via acylation of amine 156, underwent IMDA reaction in situ to generate fused tricycle 158. The $\pi$-diastereofacial selectivity of this transformation appears to arise from a preference for a staggered conformation across $\mathrm{C} 12-\mathrm{C} 13-\mathrm{C} 17-\mathrm{C} 20$, with the tether carbonyl endo in transition state TS-158. A further three steps gave isocyanate $\mathbf{1 5 9}$, which underwent an intramolecular Friedel-Crafts reaction to give pentacycle $\mathbf{1 6 0}$.

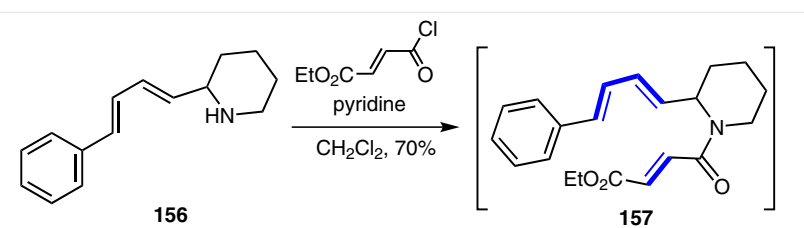

156

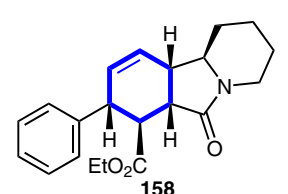

3 steps

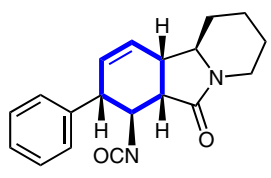

159
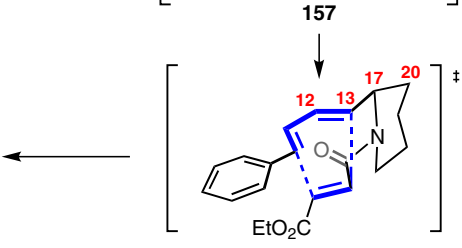

TS-158

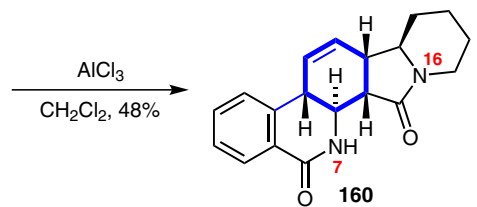

Scheme 37 Gschwend's 1973 IMDA approach to 7,16-diazasteroids

This concludes the section of this review focusing on the use of a single DA reaction in the construction of a steroid six-membered ring. The variety of approaches covered so far reveals the tremendous power and versatility of this transformation, and highlights the ingenuity of the chemists involved in inventing these approaches.

\subsection{Double Diels-Alder Sequences}

A single DA reaction generates two new covalent bonds and at least one six-membered ring. The preceding sections of this review have underlined the benefits to steroid synthesis when deploying a single cycloaddition event. Of course, the use of two DA reactions should lead to even more efficient steroid syntheses.

Examples of steroid syntheses involving two DA events separated by other reactions have been reported, as have the use of two DA reactions in successive synthetic steps. The latter category reaches its natural conclusion in domino sequences.

One steroid synthesis featuring two separated DA reactions is Rodrigo's 2009 approach to furanosteroid natural products $^{151}$ (Scheme 38 ). In this extraordinarily step-economical approach, catechol $\mathbf{1 6 1}$ was oxidized to 0 -quinone 162, which underwent a site- and regioselective DA reaction with diene 163, followed by in situ decarboxylation and re-aromatization to give catechol 165. A further four steps were required to access phenol 166, which was primed for the second DA reaction. Oxidation of this substrate with bis(trifluoroacetoxy)iodobenzene (PIFA), in the presence of diene 167, gave 0 -quinone monoketal intermediate 168, which underwent an IMDA reaction (with the 0 quinone monoketal as the diene) to give bridged system 169. This intermediate was heated to $120^{\circ} \mathrm{C}$ in tetrachloroethane to facilitate a Cope rearrangement (generating transient pentacycle 170), which was followed by loss of methanol and aromatization, providing pentacycle $\mathbf{1 7 1}$ in $24 \%$ yield from tricycle 166. Interestingly, if the 0 -quinone monoketal had reacted as the dienophile, rather than the diene, target $\mathbf{1 7 1}$ would have been formed directly from 168. Indeed, this IMDA adduct was obtained as a minor product from the PIFA-mediated reaction between 166 and 167, albeit in a modest 5\% yield. Rodrigo's furanosteroid synthesis is an exquisite composition, featuring a first DA reaction to form the C-ring directly, and a second to form a non-skeletal ring en route to the A-ring.

A very different synthesis of the steroid framework that employs two DA reactions is the diene-transmissive DielsAlder (DTDA) sequence reported by Fallis and co-workers. ${ }^{152-154}$ The term DTDA was originally coined by Tsuge and co-workers in $1983 .{ }^{155}$ Cross-conjugated triene 172 was prepared in enantiopure form from L-arabinose (Scheme 39). A Swern oxidation gave enone 173, which underwent an IMDA reaction in situ to give endo adduct 174 through tether boat conformation TS-174. IMDA adduct 174 was then treated with the dienophile $\mathrm{N}$-phenylmaleimide, which reacted at the newly formed semicyclic diene to give the endo DA adduct, 16-azasteroid 175 in excellent yield. The dienophile approaches the less sterically hindered, convex $\pi$-diastereoface of the diene in this second cycloaddition. By varying the dienophile, Fallis was able to prepare several steroid analogues. This is a powerful sequence, as it 


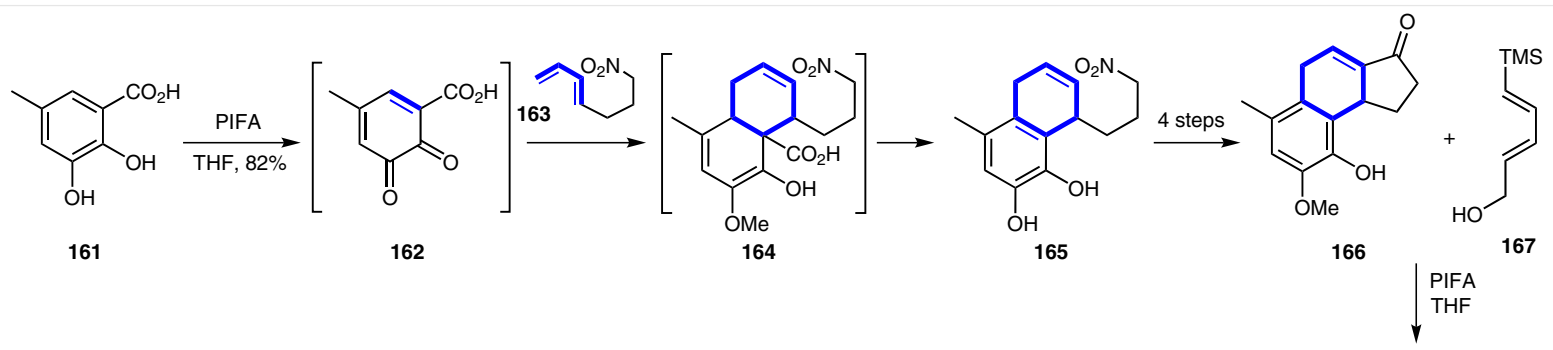<smiles>CC(C)C1CC(=O)c2ccc3c(c21)C(=O)c1occ2c1[C@H]3[C@H](C)C=C2</smiles>

171

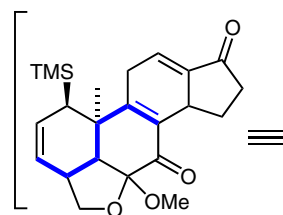

170

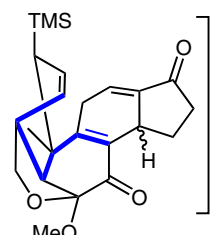

170

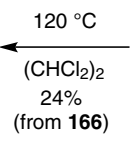

rom 166)

Scheme 38 Rodrigo's 2009 double DA approach to the steroid skeleton

generates the tetracyclic system in only two synthetic steps from the cross-conjugated triene 172. The two cycloaddition reactions, performed in consecutive steps of the synthesis, directly generate the B- and C-rings of the steroid framework as well as the A-ring, indirectly.<smiles>O[C@H]1COC[C@@H](O)[C@H]1O</smiles><smiles>C=CC(C=C)=CC(OC)[C@H]1OC(C)(C)O[C@H]1[C@H](O)CCC</smiles>

$(\mathrm{COCl})_{2}$, DMSO, $\mathrm{Et}_{3} \mathrm{~N}$ $\mathrm{CH}_{2} \mathrm{Cl}_{2}, 78 \%$

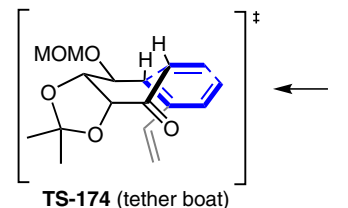

TS-174 (tether boat)<smiles>C=CC1=CCC[C@H]2C(=O)[C@@H]3OC(C)(C)O[C@@H]3[C@H](OC)[C@H]12</smiles>

174

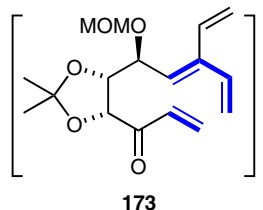

173

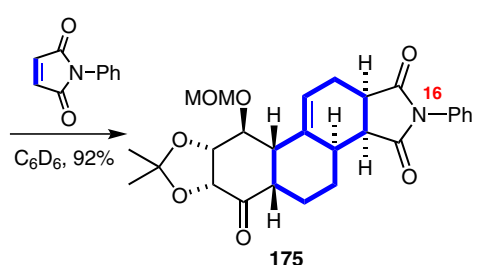

Scheme 39 Fallis's 1999 diene-transmissive double DA approach to the 16-azasteroid framework

The first report of a target-oriented application of a DTDA sequence was Sherburn's 2008 formal synthesis of the 16-oxasteroid, triptolide (Scheme 40). ${ }^{156}$ The key precursor, disubstituted [3]dendralene 176, was prepared in six steps from ethyl glycolate using Ramirez olefination and cross-coupling chemistry. ${ }^{157}$ An initial intermolecular DA reaction with the dienophile methyl acrylate generated a cycloadduct which underwent in situ lactonization to gen- erate bicycle 177. A second DA reaction, with substituted benzoquinone dienophile $\mathbf{1 7 8}$, generated tetracycle $\mathbf{1 7 9}$, completing the formation of the carbon framework of triptolide. A series of functional group manipulations gave compound 180, an intermediate from the 1982 synthesis of the natural product by Berchtold and co-workers. ${ }^{158}$ This sequence of two cycloadditions, interrupted by a lactonization, directly installed the B- and C-rings of the C16-oxasteroid skeleton in two synthetic operations from acyclic precursor 176.
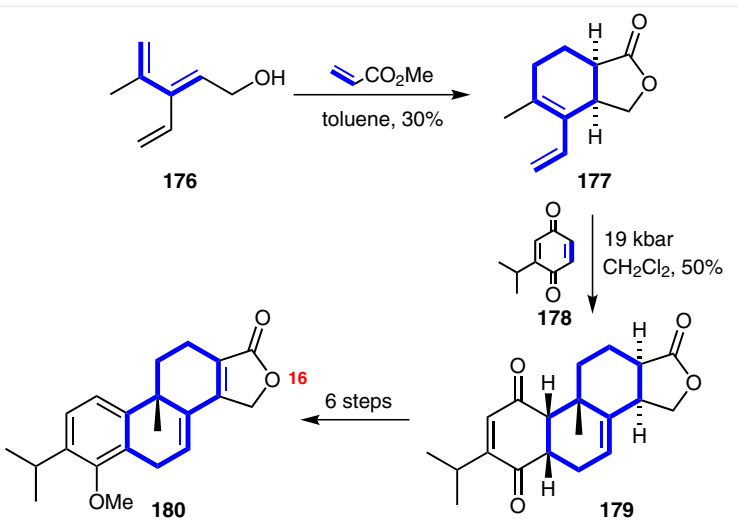

Scheme 40 Sherburn's 2008 diene-transmissive double DA approach to triptolide

The synthetic approaches discussed thus far in this section feature two separate cycloaddition events. The remaining examples in this review constitute domino cycloaddition sequences: specifically, processes in which two cycloadditions are carried out without isolation of the first DA cycloadduct.

Steroid frameworks can be formed in one synthetic operation through double dehydro-DA sequences involving 1,5-dien-3-ynes. This transformation was first described by Blomquist and Marvel in 1933. ${ }^{159}$ Further contributions 
were made in the 1940 s and 1950 s, ${ }^{160-164}$ and an isolated report appeared in $1996 .{ }^{165}$ The most recent investigation of this transformation was published by Paddon-Row and Sherburn in 2009. ${ }^{166}$ The reaction of bicyclic dienyne $\mathbf{1 8 1}$ with fumaronitrile to form D-homosteroid structures 183 and 184 is representative (Scheme 41 ). Two consecutive dehydro-DA reactions gave the tetracyclic double DA adducts by way of putative intermediate $\mathbf{1 8 2}$, in a reaction best performed under microwave heating. A variety of 1,5-dien-3ynes and dienophiles were used to construct a range of steroid frameworks. While this transformation is a rapid way to access the steroid system, it is limited in that the same dienophile must be used for both DA reactions.

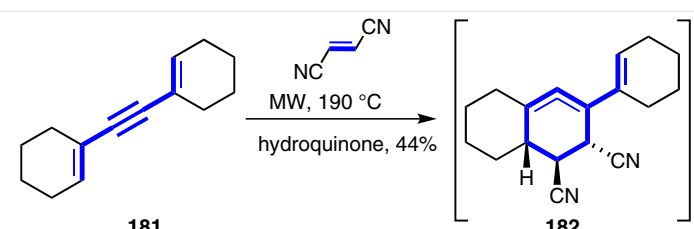

181

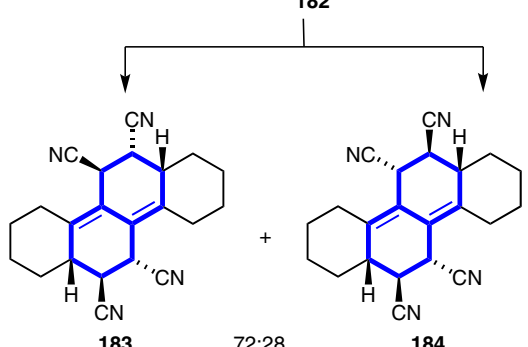

Scheme 41 Paddon-Row, Sherburn and co-workers' double dehydroDA sequence (2009)

The final double DA approach to the steroid nucleus, first described by Sherburn's research group in 2001, ${ }^{167}$ also involves a domino sequence of two DA reactions, but is a departure from the other double cycloaddition approaches in important ways. Firstly, all four rings of the steroid framework are generated in one step from an acyclic precursor. In addition, the two cycloadditions are performed in an intramolecular fashion, with the first facilitating the second, by bringing the second diene and dienophile into closer proximity. The acyclic precursor for this IMDA-IMDA sequence (188) was prepared in a convergent manner from the three building blocks 185, 186 and 187 (Scheme 42). The double IMDA sequence was achieved when achiral, acyclic hexaene 188 was exposed to diethylaluminum chloride in refluxing dichloromethane. Three (out of a possible eight) diastereomeric products were formed, with tetracyclic double IMDA adduct 190 (57\%) being the major product. This major product is generated from endo intermediate 189 (endo with respect to the tether ketone group), via the tether chair conformation illustrated (TS-190). The $\pi-$ diastereofacial selectivity of the second IMDA event arises from a preference for the staggered over the eclipsed conformation across C1-C9-C10-C11. The terminal methyl ester group adopts an endo orientation in this transition-state structure.

This double cycloaddition sequence directly forms the A- and C-rings of the steroid framework, with the B- and Drings formed indirectly. This is another $0 \rightarrow A B C D$ approach to the steroid nucleus, and one that proceeds in only two bond-forming events from the acyclic precursor.

By replacing the trimethylene tether between the double diene and double dienophile sections of precursor 189 with one that is shorter, oxygen-containing and carries a substituent (and stereocenters), the same research group have extended this work to the preparation of enantiomerically pure D-oxasteroid frameworks. ${ }^{168}$ This approach has not yet been employed in total synthesis.

\subsection{Conclusions and Future Prospects}

In composing this review, we elected to divide the steroid syntheses employing DA reactions into three general categories: those featuring a DA reaction in the direct formation of either a skeletal or a non-skeletal ring, and those employing more than one DA to the steroid nucleus. Fur-

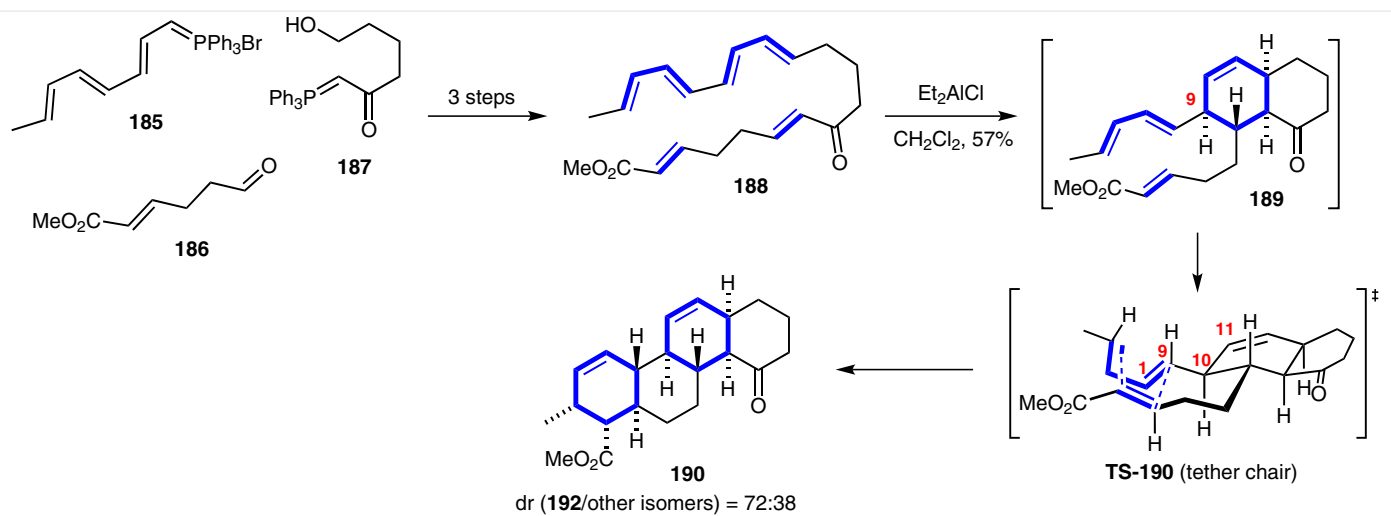

Scheme 42 The domino IMDA-IMDA approach to steroids by Sherburn and co-workers (2001) 
ther subdivisions, particularly within the skeletal ring forming syntheses, have allowed the identification of common themes and sometimes surprising associations between ostensibly unrelated work. We hope that the reader finds this approach instructive.

Perhaps predictably, the majority of synthetic approaches in the literature employ one DA reaction for the direct formation of a steroid skeletal ring. It is testament to the unparalleled synthetic power and versatility of the DA reaction that most of the possible approaches have already been examined. Nonetheless, there remain four DA disconnections of the steroid framework that have not yet been realized synthetically (Scheme 43).

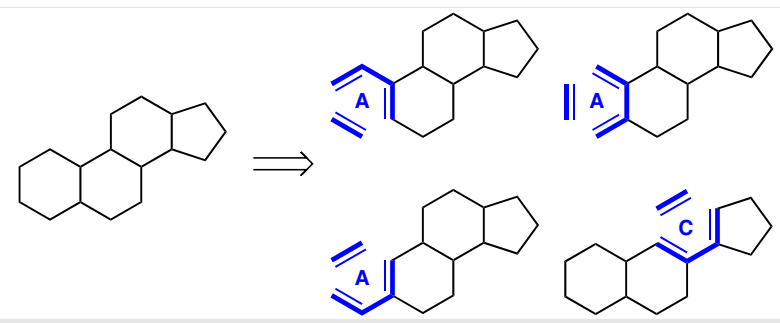

Scheme 43 The single Diels-Alder approaches to the steroid skeleton not yet reported

Three are disconnections of the A ring that leave the remaining three rings of the steroid intact, and all four approaches excise only two carbon atoms, betraying disconnections that perhaps lack significant structural simplification. Despite this qualification, each has both merit and potential and, furthermore, each represents an opportunity for an ambitious researcher to demonstrate their creativity.

We chose to cover not only total syntheses of steroids in this review but also methodology-driven work for steroid framework synthesis. In the former cases, the achievement of the target structure justifies the purpose of the work. Since the latter projects do not generate a specific target structure (say, a natural product or medicinal agent), they are presented on the basis of their potential in target-based studies.

We have attempted to identify the originators of each type of DA approach to steroids and we have made every effort to be thorough in surveying the literature. In a project of this size and breadth, we regret that there will, inevitably, be work that has been missed. We apologize for any oversights and omissions.

We conclude our analysis by asking two important but challenging questions: (a) Do DA-based approaches to steroids compare favorably with other approaches? (b) What are the best DA-based approaches to steroids?

Judging one synthesis against another will always be a subjective process. It is difficult enough to compare two approaches to the same target, and impossible to objectively compare different approaches to different targets. By what measure(s) should the judgement be made? When the step count from one approach to a specific structure is significantly lower than that of a previous approach, perhaps a case can be made to claim improvement. Even this rather blunt instrument will be seen by many as an oversimplification, since overall yield, ability to perform on scale, access to starting materials, catalysts and reagents, costs, etc. could easily be factored into the assessment.

It is also not reasonable to compare, say, the step-economical synthesis of a steroid framework with a total synthesis of a specific target structure, and it is hardly fair to compare a steroid synthesis reported in the 1950s with a recently published example.

With these caveats in mind, we are willing to answer the questions and make some subjective observations. Do DA-based approaches to steroids compare favorably with other approaches? Yes and no. There can be no doubt that vital contributions have been made in this field. Few would argue that Woodward's achievements (Scheme 2) were anything less than revolutionary. Vollhardt's 1980 synthesis of estrone (Scheme 23) rightfully deserves to be seen as a high point, not only in steroid synthesis but in total synthesis more generally. That it remains to be bettered - by any measure - reflects both how good it is and how far ahead of its time it appeared. Within the realm of non-aromatic steroid syntheses, similar reverence is given to Johnson's 1971 biomimetic synthesis of progesterone ${ }^{169}$ and, despite many imaginative and brilliant approaches involving DA reactions, none are better.

What are the best DA-based approaches to steroids? of the single DA approaches that have been reported, intramolecular DA reactions, which form two rings in one operation, have particular prominence. We consider Stork's 1987 synthesis of adrenosterone (Scheme 4) as a triumph of synthetic design and orchestration. The IMDA reaction is set up beautifully, and only two operationally simple (but strategically brilliant) steps are needed to access the natural product. We also favor the transannular DA approach, championed largely by Deslongchamps (Scheme 33), which we regard as a particularly elegant and sophisticated approach to steroid synthesis. Kametani deserves a special mention, since his group was the first to explore several of the most important DA-based approaches to steroids. His work paved the way both for Vollhardt's estrone synthesis and the research of many others.

Finally, we favor the use of double DA sequences in steroid synthesis, not only because this area remains largely unexplored but also on account of the astonishing speed at which structurally complex polycyclic systems can be prepared. This is one way that the science of steroid synthesis can move forward. 


\section{Acknowledgment}

The authors gratefully acknowledge the financial support of the Australian Research Council.

\section{References}

(1) Moss, G. P. Eur. J. Biochem. 1989, 186, 429.

(2) Lednicer, D. Steroid chemistry at a glance; Wiley: New York, 2011.

(3) Diels, O.; Alder, K. Liebigs Ann. 1928, 460, 98.

(4) Cohen, A.; Warren, F. L. J. Chem. Soc. 1937, 1315.

(5) Ibrahim-Ouali, M. Steroids 2009, 74, 133.

(6) Woodward, R. B.; Sondheimer, F.; Taub, D.; Heusler, K.; McLamore, W. M. J. Am. Chem. Soc. 1952, 74, 4223.

(7) Ireland, R. E.; Beslin, P.; Giger, R.; Hengartner, U.; Kirst, H. A.; Maag, H. J. Org. Chem. 1977, 42, 1267.

(8) Stork, G.; Saccomano, N. A. Tetrahedron Lett. 1987, 28, 2087.

(9) Stork, G.; Clark, G.; Shiner, C. S. J. Am. Chem. Soc. 1981, 103, 4948.

(10) Burgess, E. M.; Penton, H. R.; Taylor, E. A. J. Org. Chem. 1973, 38, 26.

(11) Stork, G.; Sherman, D. J. Am. Chem. Soc. 1982, 104, 3758.

(12) Rao, G. S. R. S.; Devi, L. U.; Sheriff, U. J.J. Chem. Soc., Perkin Trans. 11991,964

(13) Rao, G. S. R. S.; Banerjee, D. K.; Devi, L. U.; Sheriff, U. Aust. J. Chem. 1992, 45, 187.

(14) Johnson, W. S.; Christiansen, R. G.; Ireland, R. E. J. Am. Chem. Soc. 1957, 79, 1995.

(15) Kirsch, G.; Golde, R.; Neef, G. Tetrahedron Lett. 1989, 30, 4497.

(16) Perez-Medrano, A.; Grieco, P. A. J. Am. Chem. Soc. 1991, 113, 1057.

(17) Fürst, A.; Labler, L.; Meier, W. Helv. Chim. Acta 1981, 64, 1870.

(18) Onyango, E. O.; Jacobi, P. A. J. Org. Chem. 2012, 77, 7411.

(19) Ihara, M.; Sudow, I.; Fukumoto, K. J. Org. Chem. 1985, 50, 144.

(20) Hajos, Z. G.; Micheli, R. A.; Parrish, D. R.; Oliveto, E. P. J. Org. Chem. 1967, 32, 3008.

(21) Caglioti, L.; Cainelli, G.; Maina, G.; Selva, A. Tetrahedron 1964, 20, 957.

(22) Ihara, M.; Sudow, I.; Fukumoto, K. J. Chem. Soc., Perkin Trans. 1 1986, 117

(23) Murata, Y.; Yamashita, D.; Kitahara, K.; Minasako, Y.; Nakazaki, A.; Kobayashi, S. Angew. Chem. Int. Ed. 2009, 48, 1400.

(24) Fang, L.; Chen, Y.; Huang, J.; Liu, L.; Quan, J.; Li, C.-C.; Yang, Z. J. Org. Chem. 2011, 76, 2479.

(25) Isaacs, R. C. A.; Grandi, M. J.; Danishefsky, S. J.J. Org. Chem. 1993, $58,3938$.

(26) Flyer, A. N.; Si, C.; Myers, A. G. Nat. Chem. 2010, 2, 886.

(27) Temmem, O.; Zoller, T.; Uguen, D. Tetrahedron Lett. 2002, 43, 3181.

(28) Temmem, O.; Uguen, D.; De Cian, A.; Gruber, N. Tetrahedron Lett. 2002, 43, 3169.

(29) Bao, J.; Dragisich, V.; Wenglowsky, S.; Wulff, W. D. J. Am. Chem. Soc. 1991, 113, 9873.

(30) Bao, J.; Wulff, W. D.; Dragisich, V. J. Am. Chem. Soc. 1994, 116, 7616.

(31) Alberola, A.; Lora-Tomayo, M.; Soto, J. L. J. Chem. Soc., Perkin Trans. 11962.

(32) Tou, J. S.; Reusch, W. J. Org. Chem. 1980, 45, 5012.

(33) Tedesco, C.; Sodano, G.; Izzo, I.; De Riccardis, F. Tetrahedron Lett. 1997, 38, 2155.
(34) De Riccardis, F.; Izzo, I.; DiFilippo, M.; Sodano, G.; DAcquisto, F.; Carnuccio, R. Tetrahedron 1997, 53, 10871.

(35) Mayer, C. D.; Bracher, F. Eur. J. Med. Chem. 2011, 46, 3227.

(36) Kolaczkowski, L.; Reusch, W. J. Org. Chem. 1985, 50, 4766.

(37) Chenera, B.; Venkitachalam, U.; Ward, D.; Reusch, W. Tetrahedron 1986, 42, 3443.

(38) Stoltz, B. M.; Kano, T.; Corey, E. J. J. Am. Chem. Soc. 2000, 122, 9044.

(39) Stoltz, B. M.; Ge, M.; Corey, E. J. Org. Lett. 2000, 2, 1927.

(40) Banwell, M. G.; Hockless, D.; Holman, J. W.; Longmore, R. W.; McRae, K. J.; Pham, H. Synlett 1999, 1491.

(41) Sünnemann, H. W.; Hofmeister, A.; Magull, J.; Banwell, M. G.; de Meijere, A. Org. Lett. 2007, 9, 517.

(42) Sünnemann, H. W.; Banwell, M. G.; de Meijere, A. Chem. Eur. J. 2008, $14,7236$.

(43) Aldegunde, M. J.; Codesido, E. M.; Castedo, L.; Granja, J. R. Tetrahedron Lett. 2006, 47, 6587.

(44) Jung, M. E.; Lui, R. M. J. Org. Chem. 2010, 75, 7146.

(45) Jacobson, B. M.; Soteropoulos, P.; Bahadori, S. J. Org. Chem. 1988, $53,3247$.

(46) Van Royen, L. A.; Mijngheer, R.; De Clercq, P. J. Tetrahedron Lett. 1983, 24, 3145.

(47) Van Royen, L. A.; Mijngheer, R.; De Clercq, P. J. Tetrahedron 1985, $41,4667$.

(48) Hildebrandt, K.; Debaerdemaeker, T.; Friedrichsen, W. Tetrahedron Lett. 1988, 29, 2045.

(49) Ghorai, B. K.; Herndon, J. W.; Lam, Y.-F. Org. Lett. 2001, 3, 3535.

(50) Tietze, L. F.; Beifuß, U.; Lökös, M.; Rischer, M.; Göhrt, A.; Sheldrick, G. M. Angew. Chem. Int. Ed. 1990, 29, 527.

(51) Bleasdale, D. A.; Jones, D. W. J. Chem. Soc., Perkin Trans. 1 1991, 1683.

(52) Bleasdale, D. A.; Jones, D. W. J. Chem. Soc., Chem. Commun. 1985, 1027.

(53) Kametani, T.; Nemoto, H.; Ishikawa, H.; Shiroyama, K.; Fukumoto, K. J. Am. Chem. Soc. 1976, 98, 3378.

(54) Kametani, T.; Nemoto, H.; Ishikawa, H. J. Am. Chem. Soc. 1977, 99, 3461.

(55) Funk, R. L.; Vollhardt, K. P. C. J. Am. Chem. Soc. 1979, 101, 215.

(56) Nicolaou, K. C.; Barnette, W. E. J. Chem. Soc., Chem. Commun. 1979, 1119.

(57) Funk, R. L.; Vollhardt, K. P. C. J. Am. Chem. Soc. 1980, 102, 5253.

(58) Grieco, P. A.; Takigawa, T. J. Org. Chem. 1980, 45, 2247.

(59) Quinkert, G.; Schwartz, U.; Stark, H. Angew. Chem. Int. Ed. 1980, $19,1029$.

(60) Kametani, T.; Matsumoto, H.; Honda, T.; Fukumoto, K. Tetrahedron Lett. 1980, 21, 4847.

(61) Doi, T.; Shimizu, K.; Takahashi, T.; Tsuji, J.; Yamamoto, K. Tetrahedron Lett. 1990, 31, 3313.

(62) Funk, R. L.; Vollhardt, K. P. J. Am. Chem. Soc. 1977, 99, 5483.

(63) Funk, R. L.; Vollhardt, K. P. C. Chem. Soc. Rev. 1980, 9, 41.

(64) Tsuji, J.; Okumoto, H.; Kobayashi, Y.; Takahashi, T. Tetrahedron Lett. 1981, 22, 1357.

(65) Cachoux, F.; Ibrahim-Ouali, M.; Santelli, M. Synlett 2000, 418.

(66) Oumzil, K.; Ibrahim-Ouali, M.; Santelli, M. Tetrahedron 2005, 61, 9405.

(67) Cachoux, F.; Ibrahim-Ouali, M.; Santelli, M. Tetrahedron Lett. 2000, 41, 1767.

(68) Cachoux, F.; Ibrahim-Ouali, M.; Santelli, M. Tetrahedron Lett. 2001, 42, 843

(69) Cachoux, F.; Ibrahim-Ouali, M.; Santelli, M. Synth. Commun. 2002, 32, 3549.

(70) Ibrahim-Ouali, M. Tetrahedron Lett. 2009, 50, 1607.

(71) Ibrahim-Ouali, M. Tetrahedron Lett. 2010, 51, 3610. 
(72) Maurin, P.; Michellys, P.-Y.; Toupet, L.; Pellissier, H.; Santelli, M. J. Org. Chem. 2001, 66, 115.

(73) Maurin, P.; Ibrahim-Ouali, M.; Santelli, M. Eur. J. Org. Chem. 2002, 151.

(74) Oumzil, K.; Ibrahim-Ouali, M.; Santelli, M. Steroids 2006, 71, 886.

(75) Ibrahim-Ouali, M.; Romero, E.; Bouleghlem, H. Tetrahedron 2011, 67, 3668.

(76) Ibrahim-Ouali, M.; Romero, E. Steroids 2012, 77, 157.

(77) Djuric, S.; Sarkar, T.; Magnus, P. J. Am. Chem. Soc. 1980, 102, 6885.

(78) Ito, Y.; Nakatsuka, M.; Saegusa, T. J. Am. Chem. Soc. 1982, 104, 7609.

(79) Oppolzer, W.; Roberts, D. A.; Bird, T. G. C. Helv. Chim. Acta 1979, 62, 2017.

(80) Nicolaou, K. C.; Barnette, W. E.; Ma, P. J. Org. Chem. 1980, 45, 1463.

(81) Andemichael, Y. W.; Huang, Y.; Wang, K. K. J. Org. Chem. 1993, $58,1651$.

(82) Lecker, S. H.; Nguyen, N. H.; Vollhardt, K. P. C. J. Am. Chem. Soc. 1986, $108,856$.

(83) Lavallée, J. F.; Deslongchamps, P. Tetrahedron Lett. 1988, 29, 6033.

(84) Deslongchamps, P. Pure Appl. Chem. 1992, 64, 1831.

(85) Couturier, M.; Deslongchamps, P. Synlett 1996, 1140.

(86) Drouin, M.; Couturier, M.; Deslongchamps, P. Acta Crystallogr., Sect. C 1997, 53, 1698.

(87) Drouin, M.; Couturier, M.; Deslongchamps, P. Acta Crystallogr., Sect. C 1998, 54, 256.

(88) Couturier, M.; Dory, Y. L.; Rouillard, F.; Deslongchamps, P. Tetrahedron 1998, 54, 1529.

(89) Couturier, M.; Dory, Y. L.; Fortin, D.; Rouillard, A.; Deslongchamps, P. Tetrahedron 1998, 54, 10089.

(90) Takahashi, T.; Shimizu, K.; Doi, T.; Tsuji, J.; Fukazawa, Y. J. Am. Chem. Soc. 1988, 110, 2674.

(91) Dane, E.; Schmitt, J. Liebigs Ann. 1938, 536, 196.

(92) Singh, G. J. Am. Chem. Soc. 1956, 78, 6109.

(93) Dickinson, R. A.; MacAlpine, G. A.; Stojanac, Z.; Valenta, Z.; Kubela, R. Can. J. Chem. 1972, 50, 2377.

(94) Takano, S.; Moriya, M.; Ogasawara, K. Tetrahedron Lett. 1992, 33 , 1909.

(95) Quinkert, G.; del Grosso, M.; Döring, A.; Döring, W.; Schenkel, R. I.; Bauch, M.; Dambacher, G. T.; Bats, J. W.; Zimmerman, G.; Dürner, G. Helv. Chim. Acta 1995, 78, 1345.

(96) Sugahara, T.; Ogasawara, K. Tetrahedron Lett. 1996, 37, 7403.

(97) Tanaka, K.; Nakashima, H.; Taniguchi, T.; Ogasawara, K. Org. Lett. 2000, 2, 1915.

(98) Canales, E.; Corey, E. J. Org. Lett. 2008, 10, 3271.

(99) Weimar, M.; Dürner, G.; Bats, J. W.; Göbel, M. W. J. Org. Chem. 2010, 75, 2718.

(100) Kakushima, M.; Allain, L.; Dickinson, R. A.; White, P. S.; Valenta, Z. Can. J. Chem. 1979, 57, 3354.

(101) Jung, M. E.; Yoo, D. Org. Lett. 2011, 13, 2698.

(102) Jung, M. E.; Guzaev, M. J. Org. Chem. 2013, 78, 7518.

(103) Goldberg, M. W.; Müller, P. Helv. Chim. Acta 1940, 23, 831.

(104) Heer, J.; Miescher, K. Helv. Chim. Acta 1948, 31, 219.

(105) Buchta, E.; Bayer, H. Chem. Ber. 1957, 90, 1647.

(106) Winternitz, F.; Diaz, J. Tetrahedron 1963, 19, 1747.

(107) Georgian, V.; Lepe, M. J. J. Org. Chem. 1964, 29, 40.

(108) Lepe, M. J.; Georgian, V. J. Org. Chem. 1964, 29, 45.

(109) Castellano, J. M.; Braña, M. F.; Lora-Tamayo, M.; Soto, J. L. Tetrahedron Lett. 1977, 18, 4141.
(110) Cohen, N.; Banner, B. L.; Eichel, W. F.; Valenta, Z. Synth. Commun. 1978, 8, 427.

(111) Das, J.; Valenta, Z.; Kubela, R.; MacAlpine, G. A.; Stojanac, Z. Can. J. Chem. 1979, 57, 3308.

(112) Bodalski, R.; Koszuk, J.; Krawczyk, H.; Pietrusiewicz, K. M. J. Org. Chem. 1982, 47, 2219.

(113) Quinkert, G.; del Grosso, M.; Bucher, A.; Bats, J. W. Tetrahedron Lett. 1991, 32, 3357.

(114) Gacs-Baitz, E.; Minuti, L.; Scheeren, H. W.; Selvaggi, R.; Taticchi, A. Nat. Prod. Lett. 1993, 2, 91.

(115) Gacs-Baitz, E.; Minuti, L.; Taticchi, A. Tetrahedron 1994, 50, 10359.

(116) Gacs-Baitz, E.; Marrocchi, A.; Minuti, L.; Scheeren, H. W.; Taticchi, A. Nat. Prod. Lett. 1994, 5, 165.

(117) Alonso, I.; Carretero, J. C.; Ruano, J. G.; Cabrejas, L. M. M.; LópezSolera, I.; Raithby, P. R. Tetrahedron Lett. 1994, 35, 9461.

(118) Rosillo, M.; Casarrubios, L.; Dominguez, G.; Perez-Castells, J. Tetrahedron Lett. 2001, 42, 7029.

(119) Aversa, M. C.; Barattucci, A.; Bonaccorsi, P.; Bruno, G.; Caruso, F.; Giannetto, P. Tetrahedron: Asymmetry 2001, 12, 2901.

(120) Essers, M.; Haufe, G. J. Chem. Soc., Perkin Trans. 1 2002, 2719.

(121) Sultani, A.; Dietrich, H.; Richter, F.; Otto, H.-H. Monatsh. Chem. 2005, 136, 1651.

(122) Harmata, M.; Gomes, M. G. Eur. J. Org. Chem. 2006, 2273.

(123) Bodtke, A.; Stubbs, M. T.; Otto, H.-H. Monatsh. Chem. 2006, 137, 83.

(124) Hessler, F.; Císařová, I.; Sedlák, D.; Bartůněk, P.; Kotora, M. Chem. Eur. J. 2012, 18, 5515.

(125) Quinkert, G.; del Grosso, M.; Bucher, A.; Bauch, M. Tetrahedron Lett. 1992, 33, 3617.

(126) Schuster, T.; Bauch, M.; Dürner, G.; Göbel, M. W. Org. Lett. 2000, 2, 179.

(127) Schuster, T.; Kurz, M.; Göbel, M. W. J. Org. Chem. 2000, 65, 1697.

(128) Shibatomi, K.; Futatsugi, K.; Kobayashi, F.; Iwasa, S.; Yamamoto, H. J. Am. Chem. Soc. 2010, 132, 5625.

(129) Schotes, C.; Mezzetti, A. J. Am. Chem. Soc. 2010, 132, 3652.

(130) Schotes, C.; Althaus, M.; Aardoom, R.; Mezzetti, A. J. Am. Chem. Soc. 2012, 134, 1331.

(131)Dzierba, C. D.; Zandi, K. S.; Mollers, T.; Shea, K. J. J. Am. Chem. Soc. 1996, 118, 4711.

(132) Bear, B. R.; Shea, K. J.; Parnes, J. S. Org. Lett. 2003, 5, 1613.

(133) Gelman, D. M.; Mayes, P. A.; Mulder, R.; Perlmutter, P. Tetrahedron: Asymmetry 2006, 17, 3341.

(134) Kametani, T.; Suzuki, Y.; Furuyama, H.; Honda, T. J. Org. Chem. 1983, 48, 31.

(135) Karras, M.; Snider, B. B. J. Am. Chem. Soc. 1980, 102, 7951.

(136) Tsuge, O.; Ueno, K.; Kanemasa, S. Heterocycles 1986, 24, 629.

(137) Xue, Y.-P.; Li, W.-D. Z. J. Org. Chem. 2011, 76, 57.

(138) Woodward, R. B. J. Am. Chem. Soc. 1940, 62, 1478.

(139) Kurosu, M.; Marcin, L. R.; Grinsteiner, T. J.; Kishi, Y. J. Am. Chem. Soc. 1998, 120, 6627.

(140) Narasimhan, N. S.; Bapat, C. P. J. Chem. Soc., Perkin Trans. 1 1984, 1435.

(141) Lu, P.; Ma, S. Org. Lett. 2007, 9, 5319.

(142) Nemoto, H.; Nagai, M.; Fukumoto, K.; Kametani, T. Tetrahedron Lett. 1985, 26, 4613.

(143) Sato, M.; Suzuki, T.; Morisawa, H.; Fujita, S. Chem. Pharm. Bull. 1987, 35, 3647.

(144) Sato, M.; Kawakami, K.; Suzuki, T.; Morisawa, H.; Nishimura, S.; Kaneko, C. Steroids 1989, 53, 739.

(145) Nemoto, H.; Nagai, M.; Moizumi, M.; Kohzuki, K.; Fukumoto, K.; Kametani, T. J. Chem. Soc., Perkin Trans. 1 1989, 1639. 
Synthesis

(146) Nemoto, H.; Satoh, A.; Ando, M.; Fukumoto, K. J. Chem. Soc., Perkin Trans. 1 1991, 1309.

(147) Kobayashi, K.; Itoh, M.; Suginome, H. J. Chem. Soc., Perkin Trans. $11991,2135$.

(148) Ouellet, L.; Langlois, P.; Deslongchamps, P. Synlett 1997, 689.

(149) Beaubien, S.; Deslongchamps, P. Can. J. Chem. 2006, 84, 29.

(150) Gschwend, H. W. Helv. Chim. Acta 1973, 56, 1763.

(151) Lang, Y.; Souza, F. E. S.; Xu, X.; Taylor, N. J.; Assoud, A.; Rodrigo, R. J. Org. Chem. 2009, 74, 5429.

(152)ApSimon, M.; Souweha, M. S.; Arab, A.; Fallis, A. G. Org. Lett. 2007, 9, 615.

(153)Clay, M. D.; Riber, D.; Fallis, A. G. Can. J. Chem. 2005, 83, 559.

(154)Woo, S.; Legoupy, S.; Parra, S.; Fallis, A. G. Org. Lett 1999, 1, 1013.

(155) Tsuge, O.; Wada, E.; Kanemasa, S. Chem. Lett. 1983, 12, 239.

(156) Miller, N. A.; Willis, A. C.; Sherburn, M. S. Chem. Commun. 2008, 1226.

(157) Cayzer, T. N.; Wong, L. S. M.; Turner, P.; Paddon-Row, M. N.; Sherburn, M. S. Chem. Eur. J. 2002, 8, 739.
(158) Lai, C. K.; Buckanin, R. S.; Chen, S. J.; Zimmerman, D. F.; Sher, F. T.; Berchtold, G. A. J. Org. Chem. 1982, 47, 2364.

(159) Blomquist, A. T.; Marvel, C. S. J. Am. Chem. Soc. 1933, 55, 1655.

(160) Butz, L. W.; Gaddis, A. M.; Butz, E. W. J.; Davis, R. E. J. Org. Chem. 1940, 5, 379.

(161) Butz, L. W.; Joshel, L. M. J. Am. Chem. Soc. 1941, 63, 3344.

(162) Butz, L. W. J. Am. Chem. Soc. 1942, 64, 1311.

(163) Butz, L. W.; Gaddis, A. M. J. Am. Chem. Soc. 1947, 69, 924.

(164) Ray, F. E.; Sawicki, E.; Borum, O. H. J. Am. Chem. Soc. 1952, 74, 1247.

(165) Ionescu, D.; Silverton, J. V.; Dickinson, L. C.; Miller, B. Tetrahedron Lett. 1996, 37, 1559.

(166) Fallon, T.; Robinson, D. E. J. E.; Willis, A. C.; Paddon-Row, M. N.; Sherburn, M. S. Chem. Eur. J. 2010, 16, 760.

(167) Nörret, M.; Sherburn, M. S. Angew. Chem. Int. Ed. 2001, 40, 4074.

(168) Turner, C. I.; Williamson, R. M.; Turner, P.; Sherburn, M. S. Chem. Commun. 2003, 1610.

(169)Johnson, W. S.; Gravestock, M. B.; McCarry, B. E. J. Am. Chem. Soc. 1971, 93, 4332. 